Nature as Nurture: Rural Older Women's Perspectives on The Natural Environment

\author{
Erica Kathryn Husser
}

Dissertation submitted to the faculty of the Virginia Polytechnic Institute and State University in partial fulfillment of the requirements for the degree of

Doctor of Philosophy

In

Human Development

Adult Development and Aging

Dr. Karen A. Roberto, Chair

Dr. Katherine R. Allen

Dr. Shannon E. Jarrott

Dr. Barry A. Garst

September 4, 2009

Blacksburg, Virginia

Keywords: Nature, Environment, Aging, Rural, Women, Qualitative, Life Course Perspective, Restoration, Place

Copyright 2009, Erica K. Husser 


\title{
NATURE AS NURTURE: RURAL OLDER WOMEN'S PERSPECTIVES ON THE NATURAL ENVIRONMENT
}

\author{
Erica Kathryn Husser
}

\begin{abstract}
The natural environment is a dynamic context for human development, but current lifestyles and activities are threatening the quality and supply of natural resources, and changing the conditions of the atmosphere. Older adults in the United States have been called upon to contribute their energy to volunteer efforts aimed at improving environmental conditions, but little is known about how or if older adults would be willing to take part. Informed by place attachment and attention restoration theory, and guided by the life course framework of human development, the purpose of this qualitative investigation was to deepen understanding about how a nature trajectory is established and the factors that influence the relationship between humans and nature over time.

Interviews were conducted with 34 older rural women who ranged in aged from 71 to 91 years old (mean age 79). Seventeen of the women were living alone and nine lived below the poverty threshold. Using grounded theory coding and analysis techniques, two major findings emerged from the data: the women valued nature for spiritual and psychological reasons, and nature was suffering as a result of a wasteful and destructive economic paradigm. Half of the women's nature trajectories changed over time; trajectories remained positive and stable for the others. As God's creation, the natural environment informed their sense of self and bolstered their psychological well-being. They cared about environmental problems, but were unaware of what they could do to help.
\end{abstract}




\section{TABLE OF CONTENTS}

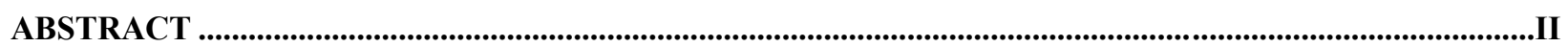

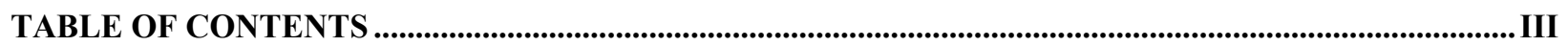

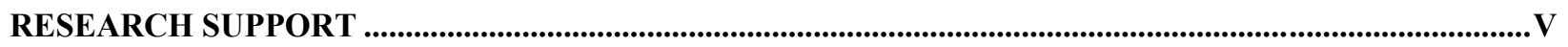

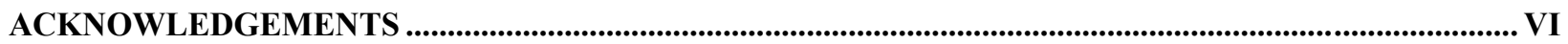

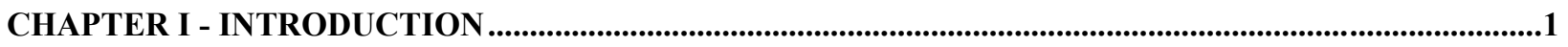

CHAPTER II - THEORETICAL FRAMEWORKS AND REVIEW OF LITERATURE ...................................5

Theoretical Frameworks .................................................................................................. 5

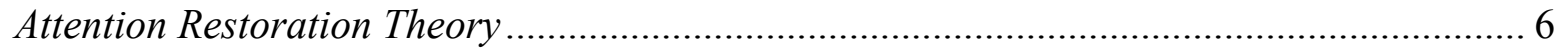

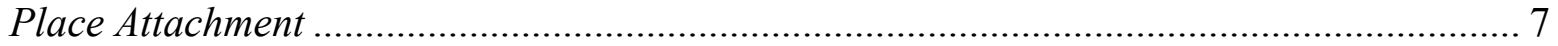

Exploring the Human-Nature Relationship: A Life Course Perspective ............................... 9

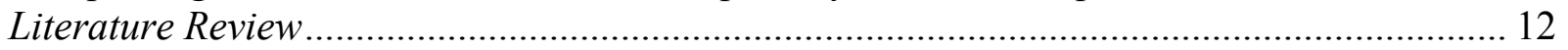

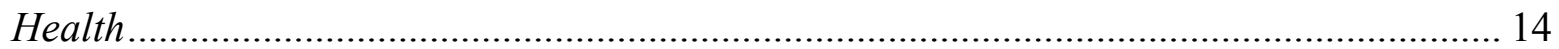

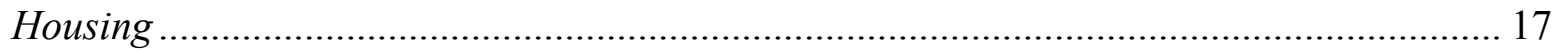

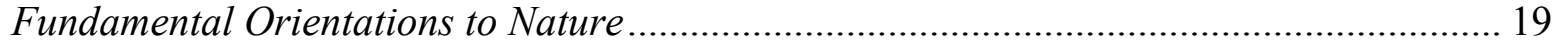

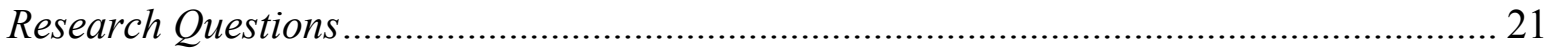

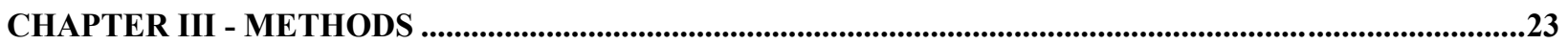

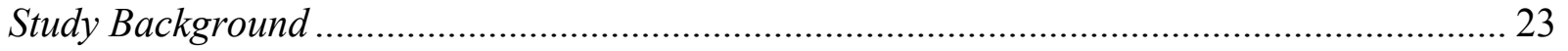

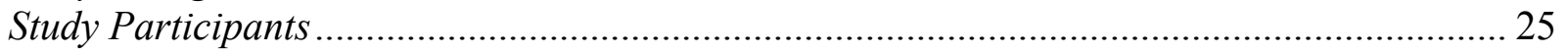

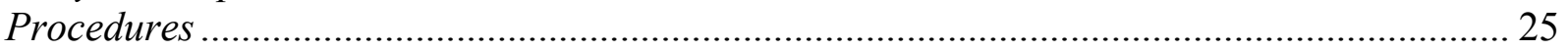

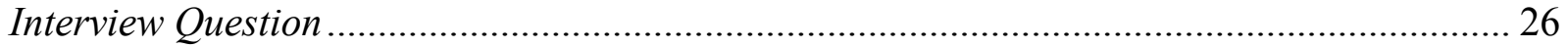

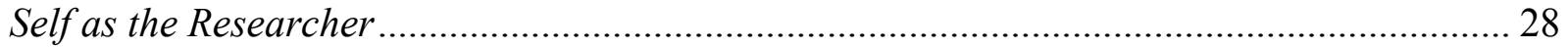

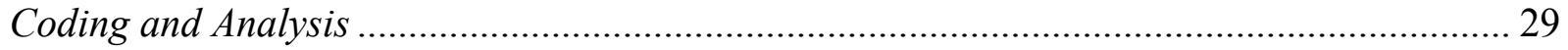

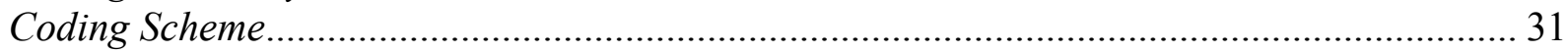

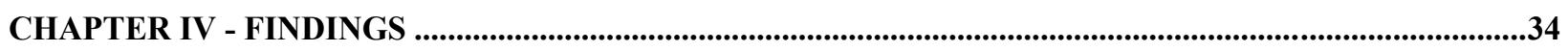

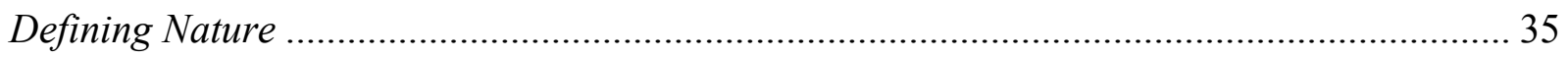

Nature Is Right Outside My Door .......................................................................... 35

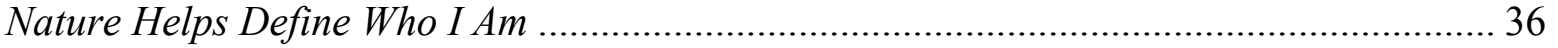

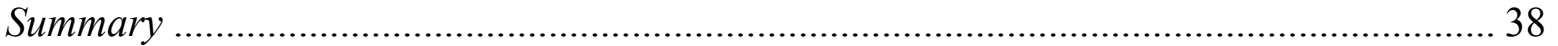

The Importance Of Nature In The Women's Daily Lives .................................................... 38

Nature Is God's Creation................................................................................................ 39

Nature Is Emotionally and Intellectually Stimulating ................................................. 44

We Depend on Nature to Survive and Thrive ............................................................... 48

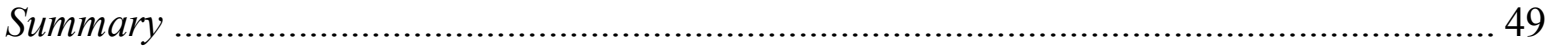

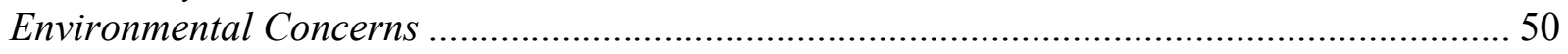

We Are Destroying Our Natural Resources.................................................................. 51

Changes to the Atmosphere and Planet ..................................................................... 54

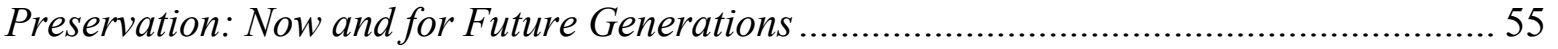

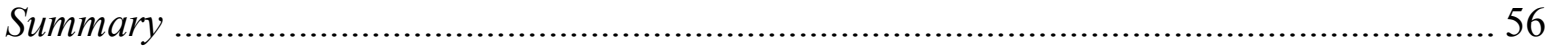

Nature Trajectory ........................................................................................................... 57

My Childhood Influenced How I Feel about Nature ................................................... 58

Nature Became More Important as I Matured .................................................................. 59 


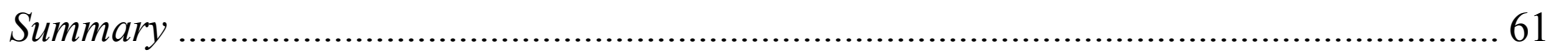

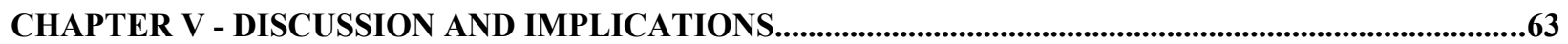

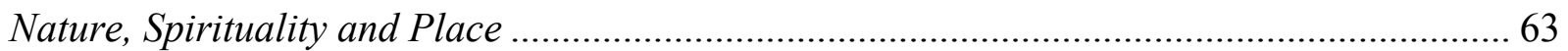

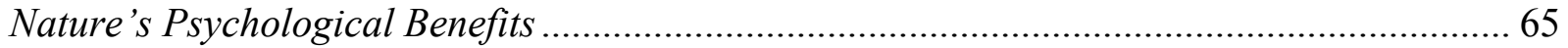

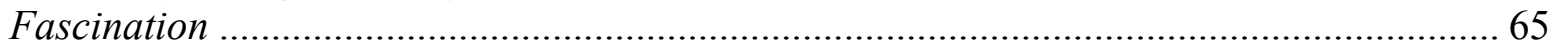

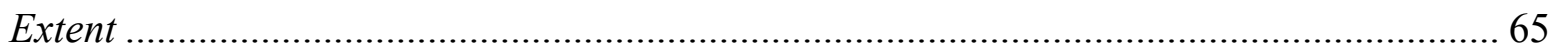

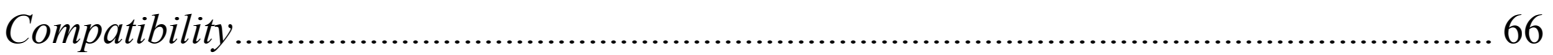

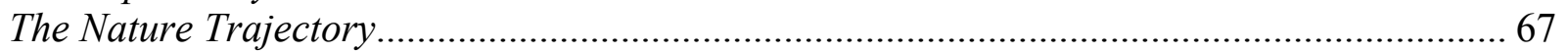

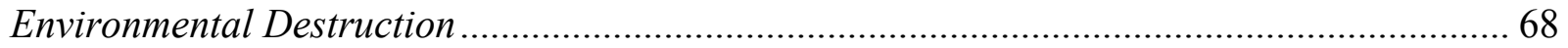

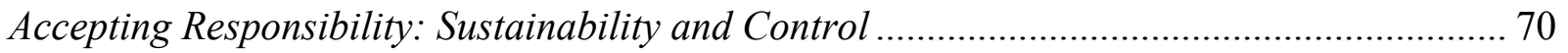

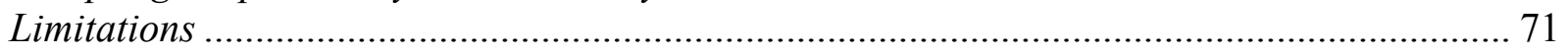

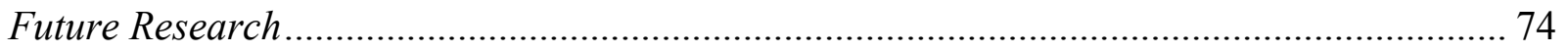

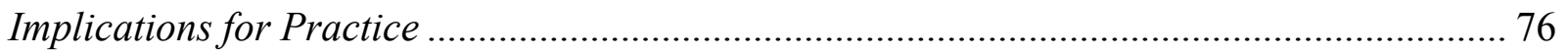

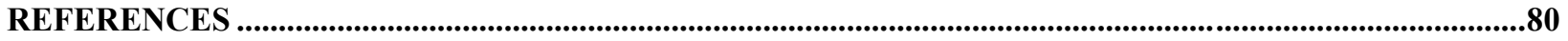

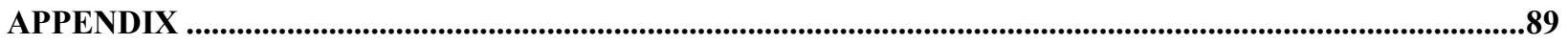

Appendix A - Institutional Review Board (IRB) Approval Form ...................................... 89

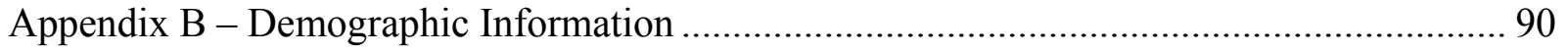

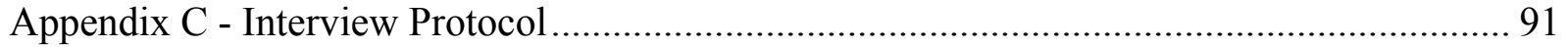




\section{RESEARCH SUPPORT}

This research was supported in part by the Cooperative State Research, Education, and Extension

Service, U.S. Department of Agriculture under Project No. VA-135688 of the Virginia Agricultural Experiment Station.

S. J. Ritchey Gerontology Graduate Certificate Student Scholarship, Center for Gerontology, Virginia Polytechnic Institute and State University, 2005, 2006, \& 2007

AARP Scholar, AARP Office of Academic Affairs, AARP, Washington, DC, 2005-2006 


\section{ACKNOWLEDGEMENTS}

I am fortunate to have been well supported intellectually and emotionally by passionate, caring, inquisitive, daring, and trusting academics. First, thank you to my advisor, Dr. Karen Roberto. Her consistency and steadiness in all matters brought stability to my mind and heart as we pursued, together, my exploration into a new area of study for both of us. Dr. Roberto trusted me to make good decisions, acknowledge when I erred, and correct what needed correcting. Her faith in my abilities, and most importantly her genuine interest in my ideas, was continuous affirmation that I was on the right track. The guidance of Dr. Katherine Allen continues to be a gift I deeply cherish. Her raw and unrelenting passion for honesty, fairness, and freedom is unsurpassed and I am continuously inspired by, challenged, and in awe of her talent for getting straight to the heart, or 'guts', of the issue. Thanks also to Dr. Shannon Jarrott who was always willing to listen and provide opportunities for learning. Her thoughtful nature and practical perspective helped keep me grounded and reminded me about the importance of making a difference in older adults' lives. And, to Dr. Barry Garst, who shares my passion for the outdoors. His vast knowledge about the subject area was greatly appreciated as he opened my mind to new ways of thinking about and exploring this line of research. I am grateful to the faculty, staff, and fellow students in the department of Human Development, with special recognition to my colleagues and friends at the Center for Gerontology.

To my family, especially my parents, Kathryn and John, who both inspired and supported me at different times in my life and in many different ways. To my grandparents, who, unknowingly, helped me appreciate the importance and strength of the life course perspective. To my brothers, who encouraged me with their enthusiasm for my journey. To my husband John: we met during this process, married, welcomed our son into this world, and I became a stepmother. Through it all, he remained supportive, encouraging, and understanding. Finally, to 
my in-laws who pleasantly surprised me with their support and encouragement. My family's energy rejuvenated my reserves and reinforced my desire to conduct this research. This work was made possible because of the strength and support of my fabulous academic, biological and marital family. 


\section{CHAPTER I - INTRODUCTION}

As a context for human development, the natural environment holds promise for nurturing positive growth. As with all living creatures, human beings depend on the natural environment to sustain life. Beyond issues of survival, interactions with nature offer more subtle and underappreciated benefits. Time spent exposed to and interacting with the natural environment can maximize the potential for health and well-being throughout the life course (Kaplan \& Kaplan, 1989, Louv, 2005; Wells \& Lekies, 2006). Unfortunately, current human activities are negatively influencing the quality and supply of our planet's natural resources and amenities, threatening the growth potential of the human community (Intergovernmental Panel on Climate Change, 2007). If the human race is to survive and thrive, human activities need modification, and making changes will require effort from individuals and groups of all ages in every home, neighborhood, business, community, region, country, and hemisphere (Intergovernmental Panel on Climate Change, 2007).

In the United States, older adults have been called on to contribute their volunteer energy toward efforts that improve environmental conditions and slow environmental degradation (Ekstrom, Ingman, \& Benjamin, 2001; Freedman, 1999). Several questions arise from this desired mobilization of America's older adults. For example, how will older adults react to this request? Are they concerned about environmental issues and sustainability? If so, what are the characteristics common to concerned older adults and how are they formed? Could those characteristics be developed in other individuals to foster stewardship? Answers to these questions are not available from the literature on aging or environmentalism.

Until recently, most scholars focused on issues related to the natural environment have ignored older adults. In the field of gerontology, the expected increase in the size of the older adult population, combined with a recognition of the seriousness of environmental issues, has 
motivated researchers to begin investigating issues that connect aging and the natural environment (Bradley, Walbeck, \& Ghiloni, 2004; Wright \& Lund, 2000). Researchers are interested in how the aging of the population will affect the natural environment, and how the natural environment may influence the lives of older adults. Outside the field of aging, where environment-behavior studies span several disciplines, research focused on, or including older adults is present in some fields, but ignored in others. For example, leisure and recreation researchers, who focus primarily on personal growth and life-satisfaction, have included older adults and considered aging in some of their research, while environmental sociologists and psychologists have largely ignored older adults over the past 20 years.

Environmental sociologists and psychologists have attempted to identify social factors and motivations toward proenvironmental behaviors, and the influence of the environment on cognition, perception, and identity formation (Bonnes \& Bonaiuto, 2002; Knopf, 1987).

Environmental sociology and psychology, disciplines whose perspectives merge with the filed of Human Development, provide a starting point useful for understanding the presence and development of values, attitudes, and concern for nature. In the 1980s, sociologists and psychologists found that age, education, geographic location, and political ideology were associated with proenvironmental behaviors and beliefs (Buttel, 1979; Mohai \& Twight, 1987). Adults aged 65 and older were found to be less concerned than younger people and rural residents were less concerned than those living in urban environments. At the time, researchers accepted the finding on age and stopped including older adults in their samples. Twenty years later, it is time to revisit those findings, and the field of Human Development offers lifespan and life course perspectives that inherently include older adults. 
Guided by the life course framework of human development, this study is a qualitative exploration of the importance of nature in the daily lives of rural older women and their concerns about the natural environment. There were several reasons for taking this approach. First, the life course perspective sensitizes investigators to change over time, with special attention to the social and cultural influences that shape, and are shaped by, individuals. A concept fundamental to the framework is the emphasis on the interconnected nature of individual development. That is, individual lives are not only intertwined with others in their immediate network (e.g., family, friends), but also are linked to meaningful social groups and geographic locations (Elder, 1998). The life course perspective also recognizes the subjective nature of reality, which lends itself to qualitative research methods. Attention to change over time, and the influences of social, cultural, and geographical context, will provide insights into how the women's current perceptions of nature were formed and influenced over time. Second, I chose qualitative research methods based on the available research on aging and the natural environment. Most investigations of aging and the environment are related to health or housing, and data were gathered primarily using quantitative methods. The nuances and subtle differences between individuals can be lost in the collection of quantitative data, a process that also mutes the voices of participants. Also, previous research that found older adults and rural residents less environmentally concerned was comparative and needs to be qualified. The findings suggested older adults do care, but why or how they cared was absent. Qualitative methods are useful for giving voice to groups who are disenfranchised, and for generating new ideas about a phenomenon that is not well understood (Charmaz, 2006). Finally, I chose to conduct my research with rural older women because (a) age and geographic location are known variables related to environmental concern, (b) the women lived in a rural area rich with natural amenities, 
and I expected they would value nature because of this, and (c) my own experiences with the natural environment have not only instilled in me a sense of stewardship, but also contribute to my own quality of life.

The purpose of this research is to explore (a) how rural older women perceive the importance of nature in their daily lives, (b) the kinds of life experiences that have influenced their perceptions, (c) their concerns about the environment, and (d) potential links between their perceptions of nature and their environmental concerns. Findings from this study will shed new light on old research findings about age, geographic location, and their relationship to environmental concern. They also will contribute to an understanding about the characteristics common in older women who are concerned about the natural environment, and how those characteristics developed and changed over time. 


\section{CHAPTER II - THEORETICAL FRAMEWORKS AND REVIEW OF LITERATURE}

In this chapter, I present my theoretical framework, literature review, and research questions. I begin by highlighting two theories commonly used to study the influences of the natural environment on human development. My theoretical framework is presented next. Tenets of the life course perspective of human development will be explained along with my perceptions about how they apply to the study of older, rural women and their relationship with the natural environment. The literature review combines findings from diverse disciplines to provide an overview of the research on the human-nature relationship. I conclude this chapter by presenting my four research questions.

\section{Theoretical Frameworks}

Environment-behavior studies have garnered significant empirical attention from diverse disciplines, but as an area of research, it is not theory rich. Multiple disciplines focused on environmental issues have used micro-theories for conceptualizing and explaining a particular phenomenon (Bonnes \& Bonaiuto, 2002; Gifford, 2002); yet these theories have differed in the level of analysis used for application and explanation. For example, micro-theories, such as Attention Restoration Theory (ART; Kaplan, 1995), represent a psychological perspective with explanatory power at the individual level. Place Attachment (Altman \& Low, 1992), while originally conceived from the individual psychological perspective, has been applied at the macro level where park managers, developers, and urban planners are concerned with community-level outcomes. And, although not a theory per se, but a tool for measuring environmental values, the New Environmental Paradigm (NEP) represents a major contribution from a sociological perspective, which has explanatory power at the group or community level (Dunlap, Van Liere, Mertig, \& Jones, 2000). Collectively, on an individual to social spectrum, these theories suggest that human beings are born with a predisposition to pay attention to nature 
in order to survive and thrive, but as development proceeds, the ways in which people come to understand and value nature becomes differentially influenced by culture, demographic characteristics, family norms and behaviors, and personal experiences. What is missing from the literature is a comprehensive theory that combines the nature and nurture perspectives to addresses the complexity of the interacting influences of human development in relationship to the natural environment (Altman, 1997; Dietz, Stern, \& Guagnano, 1998).

In this section, I describe two micro-theories commonly used for investigating the influences of nature on human development that inform this study. After reviewing Attention Restoration Theory and Place Attachment, I present a detailed explanation of the theoretical framework guiding my study: the life course perspective of human development.

\section{Attention Restoration Theory}

A growing amount of research investigating the restorative benefits of nature provides substantial evidence that time spent interacting with nature, whether engaged in active or passive activities, has positive benefits for individual health and quality of life (Hartig, Evans, Jamner, Davis, \& Garling, 2003; Jansen \& von Sadovszky, 2004; Kaplan, 2001; Tang \& Brown, 2005; Tennessen \& Cimprich, 1995). Much of this research is based on Attention Restoration Theory (ART).

The foundation for ART comes from the classic work of psychologist William James (1842-1910). James introduced the concept voluntary attention, which referred to a voluntary and necessary focus on certain events or tasks in the environment. Voluntary attention required an individual to spend energy on shutting out all competing stimuli. Stephen Kaplan (1995) noted that the term voluntary attention was confusing and renamed the concept directed attention (DA). The capacity to direct attention (CDA) allows individuals to be effective in their 
environments, but continuous use of DA eventually causes directed attention fatigue (DAF), which reduces the capacity to direct attention (CDA). DAF is a key feature of this theory. The concept bridges the gap between scholars focused on the influence of nature on stress reduction and those interested in the influence of nature to restore individuals' capacity to focus attention. DAF can be an antecedent of stress, while stress can be a cause of DAF (Kaplan, 1995). When in a state of DAF, individuals need to recover their CDA, which requires a "restorative" environment.

ART posits four components to describe a restorative environment. First, the environment must be compatible so that an individual can function easily within it. Second, the environment must inspire fascination, a naturally occurring sense of awe and interest. Third, the environment must evoke extent, giving a person the feeling of being in a whole other world, and fourth, the environment must elicit a sense of being away, as if taking a break from daily routines. The natural environment consistently elicits all four components of a restorative environment. Hartig, Kaiser, and Bowler (2001) suggested the restorative perspective as a motivator toward ecologically friendly behaviors, as opposed to a fear based or moral obligation perspectives.

Attention Restoration Theory will be useful for explaining the benefits of the women's daily interactions with nature. Because it focuses on moments in time when individuals have an experience in a restorative environment (e.g., nature), it helps provide a snapshot of the immediate benefits of their nature interactions and their motivation for engaging with nature.

\section{Place Attachment}

Place attachment (PA) refers to the phenomenon that humans, through thoughts and behaviors, become emotionally attached to places (Altman \& Low, 1992). At the core of the 
idea, is a focus on the relationship that exists between a person, or group of people, and a place, and involves an individual's personal history with a locale (Williams, 2008). Place is a complex term that encompasses multiple ideas, and can be applied to diverse settings, and it resonates with the public, making it an attractive term for researchers from several disciplines (Williams, 2008; Manzo, 2003). Concepts other than place attachment, such as 'sense of place', 'connectedness to place', and 'special place' have been used to describe a person's relationship to a place, but 'place attachment' was well articulated and has enjoyed empirical attention across disciplines.

The concepts 'place identity' and 'place dependence' inform the presence and strength of place attachment (Williams \& Vaske, 2003). Place dependence refers to the behaviors engaged in at a particular place, and place identity refers to cognitive and emotional processes related to a place (i.e., how people think and feel). Place identity is an important concept that speaks to aspects of an individual that define who they are (i.e., their self-identity) in connection with the physical environment (Williams, Patterson, \& Roggenbuck, 1992). Place identity is socially constructed over time through individual and group experiences, and is described as a component of self-identity that, when healthy, enhances self-esteem and increases a sense of belonging to one's community (Vaske \& Kobrin, 2001). In addition to the positive psychological benefits of attachment to place, it has also been suggested as a positive motivator toward environmentally friendly behaviors.

Place attachment brings focus to particular locations and in the case of this research, will inform the analysis of the women's definitions of nature and why it is important to them. The theory lends understanding about the nature of the relationship between people beyond a moment 
in time. As opposed to ART, PA has a broader focus and considers moments in time that have led to one's associations (thoughts and feelings) with a particular place.

\section{Exploring the Human-Nature Relationship: A Life Course Perspective}

The Life Course perspective offers promise to enhance explanation of the complexity of the human-nature relationship and serves as the guiding framework for this study. A life course perspective sensitizes the investigator to contextual changes over time, taking into account both family level interactions and cultural influences. In addition, it emphasizes the subjective experience of events and the social construction of the meaning of those events or phenomenon (Bengtson \& Allen, 1993; Elder, 1978). Four interrelated components of the life course perspective guide this study: time, social context, process and change, and heterogeneity. Below I explore how those concepts apply to this study.

Time. The conceptualization of time is threefold, and paramount for understanding the development of older women's connections to nature. Ontogenetic time refers to an individual's unfolding biography and assumes individual agency. For example, health status typically changes over time, differentially influencing the daily lives of older adults. Women who engage with nature to help them cope with changes in their health status are exercising agency, the ability to act positively and independently on behalf of oneself (Bengtson, Putney, \& Johnson, 2005). Generational time refers to transitions or events that occur at the family level and influence the person and their social interactions. Moving from a rural environment to an urban setting is a family level transition that influences the self, others in the immediate family unit, and extended family relationships. For example, a move to a different geographic location may influence opportunities for intergenerational family vacations in natural settings where family members share experiences and tell stories, important methods for transferring knowledge and 
values about nature to younger members of the family (Watkins, 2000). Historical time connects events in the broader social context with changes in values or roles of individuals or families. Because of the growing American population, today's older adults have witnessed a massive transition in land-use, from agricultural to residential and industrial use. Such changes may have affected access to and attitudes toward land preservation and conservation. More recently, former Vice-President Al Gore's movie, An Inconvenient Truth, and the 2007 meeting of the Intergovernmental Panel on Climate Change may influence beliefs about and feelings toward environmental issues. Regardless of the particular process or phenomenon of interest, recognizing and accounting for previous life events, with attention to the interactions of different time dimensions, provides a deep and comprehensive understanding of individual growth (Bengtson \& Allen, 1993).

Social context. Examining the social context of older women's lives is fundamental for understanding relationships with the natural environment. The meanings individuals assign to nature are constructed through the broader social structure of culture, individual social interactions, and independent exploration (Dunlap et al., 2000; Louv, 2005; Wells \& Lekies, 2006). The broader social context differentially affects individual life opportunities; human beings are born into particular social locations, described by interacting social factors such as gender, race, religion, class, geographical location, and culture. An individual's social location determines constraints and regulations toward the development of an ecologically friendly worldview and environment related behaviors.

As a social force, important people become role models in the development of an individual's nature trajectory. Role models can hinder or support the creation of opportunities for interaction with the natural environment, and are known to influence late life career choices and 
leisure activities (Wells \& Lekies, 2006). Early construction of positive attitudes toward, and knowledge about nature, provides a foundation from which individuals can begin to exercise agency, making choices toward proenvironmental behaviors. The intersection of personal agency, the influence of role models, and the broader social context interact to shape the behaviors, attitudes and values the women carry forward on their environmental trajectory (Wells \& Lekies, 2006).

Process and change. The life course perspective recognizes the dialectic of continuity and change over time. Nature-based experiences that begin in early childhood influence the likelihood of individuals continuing to engage with and value nature over the life span (Wells \& Lekies, 2006). Over time, how individuals engage with nature may change, and how much and why they value nature may also change, but a consistent interest in the outdoors is likely to remain when a positive trajectory was introduced early in life. Early childhood experiences tend to involve simple outdoor activities, such as playing in the backyard or nearby park. With increasing age, the types of activities become more advanced. In adolescence and young adulthood, outdoor experiences may include sports or leisure activities such as hiking, skiing, or boating, or extended camping trips. In mid- and late life, as individuals' energy begins to decline, people choose less active forms of nature-based activities, which may include walking, or bird watching. As the activities change, the outcomes of those activities may also change, altering the reasons why individuals value nature. Early in life, exercise or pleasure may motivate a person to become involved in outdoor activities, but in later life, memories related to earlier nature-based experiences may offer older adults a sense of continuity by providing them continued social connection with individuals who are no longer living. Memories, or a sense of connection to earlier times, people, and places, may motivate nature-based activities or be activated by 
exposure to nature (Rubenstein \& Parmelee, 1992). Several changes may occur in connection to one's relationship with nature, but a desire to remain engaged with nature is expected to remain constant.

Heterogeneity. The life course approach posits increasing diversity among individuals over time. This fourth component of the life course perspective recognizes that the women's lives become increasingly unique as individuals proceed along competing and interacting trajectories, and within social contexts that also change over time. At any point along the life span, people have to make choices that may influence their access to, or ability to engage in nature-based activities.

The life course perspective encourages a holistic framework for understanding older adults' relationships with nature, and how those relationships develop and change over time. Guided by a life course perspective, I explored the importance of nature in the daily lives of rural older women, changes in their nature trajectory, and their concerns about the environment.

\section{Literature Review}

The natural environment is a dynamic and multidimensional context for human activity and growth. For millennia, philosophers, poets, artists, political, and religious figures have created cultural artifacts meant to capture the essence of the relationship between humans and nature, but scientific inquiry furthering understanding of this relationship only began to gain momentum in the late 1960s and 70s (Knopf, 1987). Two major lines of questioning have emerged within the literature. The first involved preference and asked, "Do humans prefer natural or built environments?" Research indicated that people preferred natural landscapes that were absent of built structures. People also preferred natural landscapes that offered seclusion, stimulated exploration, elicited a sense of mystery, and allowed for navigation and functioning 
(Kaplan \& Kaplan, 1989; Knopf, 1987). The second line of questioning investigated the emerging environmental social movement. Research began with examination of the social factors related to concern for, interest in, or involvement with environmental issues. Early findings suggested age, education, geographic location, and political ideology were associated with proenvironmental behaviors and beliefs (Buttel, 1979; Mohai \& Twight, 1987). Over the past 30 years, scholars from diverse disciplines (e.g., psychology, sociology, anthropology, recreation and leisure, public health, and landscape architecture) have examined the influence of nature on various biopsychosocial outcomes, such as heart rate, blood pressure, attention, values, attitudes, well-being, quality of life, and social interaction, and how those outcomes may be related to environmental behaviors (Dutcher, Finley, Luloff, \& Johnson, 2007; Hartig et al., 2001; Oskamp, 2000; Wright, Caserta, \& Lund, 2003).

Following the trajectory of early research, current studies on the human-nature relationship can be placed into two broad categories: research targeting the outcomes of humannature relationships and nature-based interactions that support health, well-being and quality of life; and research focused on the presence and development of values, attitudes, and concern toward nature (fundamental orientations), and the relationship of those concepts to proenvironmental behaviors.

Gerontologists have been interested in outcomes of the human-nature relationship in association with health and housing. Questions have included, how can the natural environment support older adults? Are nature-based therapeutic interventions effective? Do nature-based interactions support optimal development in later life? In this section, I first review the findings from the literature on health and housing, highlighting the contributions from gerontologists. 
Second, I present findings from the research on the presence and development of fundamental orientations to nature.

Health

Exposure to the natural environment has positive health benefits that are welldocumented in the research literature, but not specific to older adults. There are two landmark studies on the health influence of nature. In 1981, architect Ernest Moore found that prison inmates with a view of rolling farmland and trees had fewer sick calls than inmates with a view of a prison courtyard. In 1984, landscape architect Roger Ulrich found that post-operative patients with a view of trees recovered, on average, a day sooner than patients with a view of a brick wall. Subsequent studies in health care settings replicated the positive effect a view of nature could have on physiological measures (e.g., simply exposing patients to photographs or paintings of natural setting reduced anxiety; see Frumkin, 2001 for a more detailed account). In addition to positive physiological health outcomes, research has also shown that viewing or interacting with nature has positive psychological outcomes, such as reduced stress, improved attention, increased positive emotions (such as joy), and a sense of connection to something outside of, and larger than oneself (Kaplan, 1995).

Conducting research with young adults involved in a wilderness program, Kaplan and Kaplan (1989) found that most individuals in the program experienced personal growth, increased self-esteem (if it was low to begin with), and developed more realistic perceptions of their own skills and abilities. From this early work, Stephen Kaplan (1995) proposed Attention Restoration Theory (ART), which has received a great deal of empirical support in the general literature. Guided by ART, Tennessen and Cimprich, (1995) found that college students with a view of nature scored better on attention tasks than students without a view to nature. Also 
guided by ART, Hartig, Mang, and Evans (1991) added physiological measures and tested the effect of nature on mood, attention, blood pressure and heart rate. Thirty-four college students were randomly assigned to one of three conditions: a nature setting, urban setting, and indoor environment. Students in the nature and urban settings walked, while those in the indoor environment relaxed. Compared to the other to groups, students who walked in a nature setting scored higher on overall happiness and positive affect, and reduced scores on anger and aggression. There were no differences in blood pressure or heart rate, but those in the nature group scored higher on measures of recovery from mental fatigue. More than a decade later, Hartig et al. (2003) conducted a similar study to compare environmental settings on measures of attention, ambulatory blood pressure, and emotion. They measured 112 students before and after they took walks - one group walked in an urban area and the other in a natural setting. Those who walked in nature showed increased positive affect, decreased anger, improved performance on an attention test, and lower blood pressure. The restoration literature provides evidence of the mind-body connection, and the restorative benefits of both active and passive engagement with nature, but only recently has ART theory been applied to studies of older adults.

Jansen and von Sadovszky (2004) conducted qualitative interviews with 30 communitydwelling older adults to assess the kinds of activities older adults considered restorative. The older adults described nature-based activities as restorative 22 times. For example, one older woman described feelings of awe and fascination when looking out at the colors of the trees and sunset while another woman described feeling closer to god when she gazed at the stars (Jansen \& von Sadovszky, 2004). Italian researchers Scopelliti and Guiliani (2005) began a two part study by asking 48 older adults to list all of the environments where they typically had restorative experiences. Data from the qualitative interviews informed their creation of scenarios, 
which the study authors then tested with a sample of 192 older adults living in the community. Also guided by ART, results from their regression analysis suggested that older adults perceived the countryside and mountains as the most restorative environments; an urban plaza and a feast in a town square as the least restorative. Scopelliti and Guiliani (2005) found that being away (i.e., taking a break from daily routines) and compatibility (i.e., the ability to function easily in the environment) emerged as consistent dimensions in every environment, regardless of the perceived restorative benefits. The authors emphasized the importance of ensuring access to restorative environments in later life.

Studies with institutionalized older adults tend to take a therapeutic view of nature-based activities, which is to investigate the role of nature for influencing healing, or quality of life within the care setting. Tang and Brown (2005) measured heart rate and blood pressure of five older women as they viewed three scenes from inside their retirement community. One of the scenes acted as a control, with no windows in the room; the two other rooms had views to a natural landscape and a built landscape. Viewing the natural landscape lowered the women's blood pressure and heart rate. Similarly, Ottosson and Grahn (2005) assessed 15 older adults' heart rate, blood pressure, and powers of concentration while they spent an hour in an outdoor garden at their retirement community compared to an hour indoors. While no significant effect was found for heart rate or blood pressure, being in the garden improved the older adults' level of concentration, and those older adults who had the highest levels of "psycho-physiological imbalance" experienced the most improvement (Ottosson \& Grahn, 2005).

Dementia care researchers have studied the effects of the natural environment on persons with late stage Alzheimer's disease (AD). Late stage AD is often accompanied by agitated aggressive behavior, which is difficult to manage and quite often results in the use of drug 
therapy and caregiver burnout (Whall et al., 1997). Whall et al. (1997) introduced elements of the natural environment during bath time, as this is when persons with late stage AD often display agitated and aggressive behavior. The introduction of bird songs, food, and plants at bath time produced powerful results: agitated and aggressive behaviors were significantly reduced in the experimental group versus the control group. Other nature-based interventions have involved gardening, or simply spending time outside. For example, Gigliotti and Jarrott (2005) compared traditional Adult Day Service (ADS) activities with horticulture therapy (HT). Older adults involved with HT activities demonstrated higher levels of productive engagement and positive affect, and lower levels of non-engagement compared to older adults involved with traditional ADS activities. Other institutionalized populations demonstrate positive benefits interacting with nature.

Collectively, these findings provide evidence of the diverse benefits that older adults in retirement communities and community dwelling older adults enjoy when they have exposure or interaction with nature. Research also suggests that older adults coping with disease symptoms may benefit even more from time spent in nature. The literature supports the value of nature for both the restorative and therapeutic health benefits individuals derive from it; access to natural spaces and places is important for maintaining the health and well-being of older adults.

\section{Housing}

Where older adults reside and the quality of their residence is an important line of inquiry in gerontology. This section describes research motivated by questions about the role of housing on well-being or quality of life and the relationship of access to nature from individual dwellings on these outcomes. 
Talbot and Kaplan (1991) were among the first scholars to demonstrate the importance of green spaces for older adults. They found that older residents living in a housing complex surrounded by accessible green spaces showed significantly higher levels of residential satisfaction compared to older residents in a neighboring complex with limited access and less green space. In addition, access to flower gardens and places to relax outdoors were very important for older adults in both complexes. Kweon, Sullivan, and Wiley (1998) surveyed 91 older adults, aged 64 to 91, living in an inner-city apartment complex and found that exposure to green common spaces was systematically associated with increased levels of social integration and a greater sense of local community. Kaplan (2001) surveyed 188 residents living in six lowrise apartment buildings; $43 \%$ of the sample was aged 50 and older. She found that a view to nature increased nature and neighborhood satisfaction, and although not statistically significant, nature contributed to well-being (e.g., a view of trees enhanced participants' sense of being at peace).

In addition to inquiry at the individual residential level, scholars have examined broader housing and community development issues, based on the potential environmental impacts of a growing aging population and geographic mobility (Bradley et al., 2004). Researchers predict that a large portion of aging baby boomers will want to move after retirement - either a short distance away from their current homes, or to smaller communities that have attractive amenities, such as lakes, clean air, and less traffic congestion. The impact of older adults relocating to popular destinations may alter the region's environmental quality and sustainability, as well as a community's ability to provide human services. The Environmental Protection Agency (EPA) has launched an Aging Initiative, which focuses on three main issues related to aging and the environment: environmental health hazards, smart growth, and civic engagement 
(United States Environmental Protection Agency, 2007). Through smart growth grant programs, the EPA is encouraging communities to plan for the aging of their populations in order to avoid environmental degradation and provide efficient housing and resource use.

\section{Fundamental Orientations to Nature}

Scholars investigating fundamental orientations toward nature are interested in furthering understanding of what motivates people to behave in ecologically friendly ways (Bonnes \& Bonaiuto, 2002). Fundamental orientations encompass concepts such as worldview, environmental concern, values, attitudes, and connection with nature. The overarching goals of research on this topic are to shed light on the relationship between these concepts and proenvironmental behaviors (e.g., recycling, donating to an environmental organization) and to establish how orientations are formed. Scholars from environmental psychology, environmental sociology, political science, and economics are all interested in this line of inquiry (Altman, 1997; Bonnes \& Bonaiuto, 2002). Those focused on macro level influences, such as environmental sociologists, emphasize the importance of cultural models of nature (e.g., an ecological world-view or spiritual model), or social variables (e.g., age, race, and socioeconomic status) for informing individual values, attitudes and levels of concern (Dunlap et al., 2000; Ignatow, 2006). Environmental psychologists focus on individual level variables (e.g., altruism, awareness, sense of responsibility, and empathy) to explain how and why people value, connect, or are concerned about nature. Although a vast amount of research exists on fundamental orientations, since the late 1980s, older adults have been excluded from study samples. Their lack of inclusion suggests either that the influence of age was well understood and did not need further exploration, or it could reflect a sampling bias that excludes older adults from research. 
Beginning with the rise of the environmental movement in the 1970s, sociologists began examining social variables related to environmental concern and identified four common predictors: age, birth cohort, geographic location, and political ideology (Buttel, 1979; Mohai \& Twight, 1987). Older adults, in general, had lower levels of environmental concern compared to their younger counterparts, those living in rural areas were less concerned than their younger counterparts living in urban areas, and individuals who held a liberal view of the world were more concerned than their more conservative counterparts. Honnold (1984) suggested two explanations for these findings: older adults were infused in the dominant social order and less likely to risk opposing the social-structure and older adults were not exposed to or involved in the "anti-establishment" politics of the late 60 s and early 70 s (e.g., the civil rights movement, women's movement, the Vietnam war protests). Generally, researchers (both sociologists and psychologists) appeared to accept this explanation and stopped paying explicit attention to the influence of age on issues related to the environment.

It is time to reconsider the role of age in relationship to fundamental orientations. Not only are today's "young" and "old" different cohorts, but the political climate is different, and advances in scientific methodologies and statistical procedures provide current researchers with access to analytical tools that are better able to tease out the nuances and influences of age. For example, using a representative national sample, Dietz et al. (1998) tested the relationship between age (among other social structural and psychological variables) and environmental behaviors and found that older adults were more likely to engage in proenvironmental consumer behaviors than any other age group, a finding contrary to past research.

In the lone study published in the past decade on older adults' attitudes and concern for nature, Wright et al., (2003) surveyed a group of older adults living in the "New West" (i.e., 
Utah), where migration patterns are putting pressure on natural resources. The authors found that religious affiliation and length of residency were most strongly correlated with attitudes and concern. Older adult residents who were newest to the area and did not hold any particular religious affiliation were most positive and supportive of environmental issues. In addition, older adults tended to trust industry and business to care for the environment; they were only compelled to act on behalf of the environment when negative environmental consequences for others were assumed, and they felt a personal responsibility. The authors acknowledged their low response rate and a lack of diversity in their sample (most of the sample were Mormon, White, married, and well educated), but emphasized the complexity and diversity of responses within the sample. They concluded that a one-size fits all model of environmental concern does not exist among older adults, and that environmental issues are important for understanding the wellbeing and quality of life of current and future generations of older adults.

\section{Research Questions}

The literature focused on the role of nature in the lives of older adults generally supports the utility and importance of access to nature, but the evidence is thin and several questions have yet to be addressed. For example, how does geographic location influence the relationship between older adults and nature? How and when are orientations to nature formed? Are they static or do they change over time? What kinds of influences and experiences launch individuals onto a positive nature trajectory? In this study, I begin to explore these issues by examining rural older women's relationships with the natural environment. Specifically, the following research questions will be addressed: (1) how do older rural women define the natural environment? (2) How do older rural women perceive the importance of the natural environment in their daily 
lives? (3) In what ways are older rural women concerned about global environmental issues? (4) What influenced the way the women currently think and feel about the natural environment? 


\section{CHAPTER III - METHODS}

In this chapter, I describe the data for this study, which were collected as part of a larger five-year study lead by Karen A. Roberto, director of the Center for Gerontology at Virginia Tech. I will first present background on how the project evolved and my involvement since joining the Center for Gerontology as a graduate research assistant in 2004. I will then provide demographic information about the 34 women in my sample, outline the procedures for data collection, describe the interview protocol and questions, and provide the analysis and coding scheme.

\section{Study Background}

The data for this study was collected as part of a 5-year mixed methods investigation of behavioral and psychosocial influences on rural older Virginian's quality of life when living with multiple chronic health conditions. In 2000, using a targeted random sampling design, researchers at the Center for Gerontology at Virginia Polytechnic Institute and State University (Virginia Tech) generated a database of 2,034 older adults living in southwest Virginia (details of sampling strategy reported in Blieszner, Roberto, \& Singh, 2001-2002). Persons 65 years of age or older participated in a telephone interview concerning their health and care needs.

From the original database, 596 individuals were identified as having heart disease, osteoporosis, or diabetes. In 2003, 268 of these individuals (214 woman and 54 men) agreed to participate in a 20-minute structured telephone interview that assessed how each of the targeted diseases influenced their daily lives, including their use of health care and community services, and their interactions with family and friends. Based upon the findings, the study's primary investigator (Roberto) chose to conduct face-to-face qualitative interviews with a sub-sample of women to gain a deeper understanding of how the issues, symptoms, and challenges of each chronic disease interacted and, when considered as a whole, influenced their daily lives. The 
hypothesis was that coping with multiple chronic diseases created complex management regimes, and that an accumulation of conditions would magnify their influence on daily functioning, which could compromise older women's quality of life.

In 2004, I joined the research team and helped conduct in-depth face-to-face interviews with 58 of the 136 women living within a 90-mile radius of Virginia Tech ( $43 \%$ response rate). By design, only women living within a 90-mile radius of the University were invited to participate in this phase of the project. Of the 136 women eligible to participate, ten (7.4\%) could not be reached due to incorrect or disconnected numbers and five (3.7\%) had died since the telephone interview. Reasons given for not participating were disinterest (28.7\%) and poor health $(10.3 \%) ; 7.4 \%$ of the women gave no explanation for refusing to be interviewed (Roberto, Gigliotti, \& Husser, 2005). Our analyses of the qualitative interview data revealed three overarching findings: the women had a difficult time attributing problems or symptoms to one specific disease; they perceived their health holistically and employed a combination of both cognitive and behavioral coping strategies for managing their health in totality; and the provision of family support was not always simple or smooth. From these findings, we found ourselves considering a new theoretical framework that would help explain how older adults adapt to daily life with multiple chronic conditions (Roberto \& Husser, 2007; Roberto, 2009).

In 2006, I and another interviewer went back into the field to test our theoretical framework and ask follow-up questions of the women. I generated a series of open-ended questions about the natural environment that was included as part of the interview protocol. We conducted face-to-face in depth interviews with 36 of the 58 women interviewed in 2004 (62\% response rate). Attrition occurred as a result of disconnected telephone numbers for six women, death of five women, poor physical or cognitive health of five women, and the inability of six 
women to schedule the interview during the data collection period. The primary data for this qualitative dissertation are from 34 women's responses to my questions about nature. Two of the 36 women interviewed did not complete the nature portion of the interview protocol and were not included in this analysis.

\section{Study Participants}

All 34 women lived in rural Southwest Virginia and had lived in the same county for an average of almost 49 years (range from 2 to 83 years). All of the women were Caucasian, and ranged in age from 71 to 91 years old, with a mean age of $79(\mathrm{SD}=5.38)$. One-half $(50 \%)$ of the women lived alone. Four of the women (11\%) did not complete high school, 17 (50\%) graduated from high school or had vocational training, and $13(38 \%)$ had at least some college. Nine (27\%) of the women had incomes of less than $\$ 1,000$ per month, 13 (38\%) between $\$ 1,000$ and $\$ 2,000$ per month, and $12(35 \%)$ had monthly incomes greater than $\$ 2,000$. Pseudonyms are used in the presentation of the findings to protect the women's identities. The background characteristics for each of the women are provided in Appendix B.

\section{Procedures}

Upon approval from the Virginia Tech Institutional Review Board, in-depth face-to-face interviews with the women began in the spring of 2006. I conducted 26 of the 36 interviews collected. We sent the women holiday greetings from the Center for Gerontology in December of 2005 , which included a message about our intent to contact them in the spring for another interview. We called the women to schedule interviews; all but one interview was conduced at the women's homes (one woman was interviewed at a rehabilitation center where she was recovering from major heart surgery). When the interviewer arrived at the women's home, she received informed consent for both the interview and for permission to take photos of them in 
their home environments. Post-interview field notes were recorded in the women's file to summarize the interview and to note contextual data or observations that were neither captured during the interview, nor gleaned from photographs (for example, one women was meticulous about her house and before the interview began, she voiced concern about the interviewer scratching her kitchen table with the tape recorder). On average, the interviews took two hours to complete. They were recorded using a cassette-tape recorder and transcribed verbatim by a professional transcriptionist. Members of the research team (research assistants) verified each interview by checking the transcripts against the tapes to ensure accuracy, then formatted the transcripts by topic and uploaded them into Atlas.ti. (Muhr, 2004) for data management and analysis. The research team (the primary investigator, Dr. Roberto, myself and one other research assistant) met weekly to debrief, review progress, and discuss salient themes and issues emerging from our interview data. The weekly meetings provided the interviewers with opportunities to share their experiences and learn helpful interview strategies from one another (e.g., how to stay on track while simultaneously allowing women to take their own direction from open-ended questions).

\section{Interview Question}

The 2006 interview protocol included open-ended questions, quantitative scales, and physical measures. The interview began with a preamble in order to relax the women and inquire about what their lives had been like in the two years since we had spoken to them. We asked the women how they had been doing since we last interviewed them, and what kinds of major life events had occurred. After these initial questions, the women were asked questions under five broad categories: (1) health and coping, (2) social support network structure and dynamics, (3) the natural environment, (4) quality of life, and (5) demographic updates. Upon completion of 
the interviews, the women completed two measures of physical functioning and had their pictures taken for use in research presentations.

The nature section of the interview protocol (Appendix C) included two closed- and five open-ended questions. The women were first asked to rate, on a 7-point scale how important the natural environment was to them $(0=$ not important at all to $6=$ extremely important $)$. Probing questions followed such as, "what did you think of when I first said natural environment?", “why do you think nature is important to you?", and "have you always felt this way about nature?" Once the conversation about the importance of nature to them was complete, the interviewer asked the women to rate, again on a 7-point scale, how concerned they were about the health of the global environment $(0=$ not concerned at all to $6=$ extremely concerned $)$. Open-ended questions that followed included, "what is it about the global environment that you are concerned about?" and "have you always felt this way?" The women's responses and experiences guided subsequent questions and prompts. The portion of the interview dedicated to these questions was approximately 20 minutes.

As I created open-ended questions to investigate the importance of nature in the lives of the women, I assumed I was thinking independently and was taking a phenomenological approach. As data collection continued, and initial themes began to emerge, I noticed that asking the women about change over time was central to the life course perspective. I recognized that influences related to ontogenetic, generational, and historical time were emerging from the data and I began to realize that life course theory had implicitly influenced the development of my research questions. 


\section{Self as the Researcher}

I perceive myself as a student in all relational situations, which includes the interviews I conducted for this investigation. As the interviewer, I was not an objective observer, but a student on a journey toward understanding the lives of the women I had the fortunate opportunity to explore. The subjective experience of a relationship is co-constructed, and I brought my own bias into the dialogue, which means that I, the interviewer, influenced the responses of the women in this study. As social scientists, the challenge of producing good work involves being transparent, and reflecting on how personal experiences influence the research process (Allen, 2000).

As a nature enthusiast, I brought my own bias into the interview process, and tried remained conscious of my perspective as the interview proceeded. My experiences outdoors began at a young age, and have continued throughout my life. When I reflect on those experiences, I recall positive outcomes regardless of how much I enjoyed the individual experiences. To me, nature is authentic and when able to choose, I opt to spend my time immersed in the natural environment because it humbles me and helps me keep my life in perspective. I have placed myself in situations where for days I have had nothing but the pack on my back for survival; indeed I have been responsible for children in similar situations. Why did I choose those experiences? They were rich and complex and they helped me grow as an individual, in confidence, physical strength, and character. I am grateful for the times I have spent immersed in natural settings, often at the mercy of the elements, but also five minutes from a car that could take me back to civilization. Nature reminds me that as a human being, I only have so much control over what happens in this life. Past experiences that informed my outlook on nature, coupled with my intellectual understanding of current environmental problems, 
motivates my sense of stewardship and my desire to contribute my intellectual energy toward potential solutions that will help ameliorate the negative influence that human activity is currently having on the planet.

I conducted the majority of the interviews for this investigation, and for most of the women, it was the second time I had interviewed them in a period of 2 years. Most of the women remembered me as soon as they saw my face, and not only was the rapport immediately reestablished from the first interview, but most women seemed to relax quickly. I felt that the second time around both the women and I felt more comfortable with the process, which allowed honest, reflective, and sincere responses from the women, and better follow up questions from me.

After the interviews, I recorded field notes, noting my own reactions to the women's responses. Throughout the analysis process, I continued to practice reflexivity, which meant remaining conscious of how my own thoughts and feeling were influencing my interpretation of the data. In my efforts to remain grounded in the data, I constantly looked for alternative explanations or patterns. In addition, to add credibility to the process, two colleagues assisted me with coding data and verifying the analysis.

\section{Coding and Analysis}

I began the coding and analysis process using an open coding technique, which involved reading and re-reading each of the 34 transcripts several times, while making notes of the women's ideas, use of language, trends and storylines (Charmaz, 2006; Rossman \& Rallis, 2003). After completing the open coding, I created a table documenting the women's responses to why nature was important and what their concerns were. The purpose of the table was to provide tallies for the open codes in order to obtain an initial visual sense of how prevalent the 
codes were. At that point, to ensure dependability, I enlisted the assistance of a researcher (not on the research team) who had experience with qualitative and nature-related research (e.g., horticulture therapy). She began by completing her own independent open coding process. We compared notes and then merged our initial ideas to create the first coding scheme. Separately, we applied the coding scheme to the same two transcripts, noting the weaknesses, strengths, and nuances of each code. We exchanged our coded transcripts and compared each other's coding of the data (using electronic notation to keep track of the process), then reviewed them together to discuss congruencies and differences and refine the coding scheme. The initial coding scheme consisted of 11 themes, but after seven iterations, they were reduced to seven major themes. Using that coding scheme, we continued the process of coding and recoding the data until we reached $100 \%$ consensus, thus deepening the study’s rigor (Anfara, Brown, \& Mangione, 2002). Also, to ensure transparency, I maintained an audit trail, writing methodological and analytical memos throughout the process (Charmaz, 2006; Rossman \& Rallis, 2003). Once the data were coded, it was entered into Atlas.ti (Muhr, 2004) to manage, sort, and explore trends in the data.

After an incubation period of approximately six months (the project was put on hold while I started a family), I re-examined the coding scheme and proceeded to engage in focused coding (Charmez, 2006). Using Atlas.ti (Muhr, 2004) to sort the data into the seven themes, I reread all of the data by theme, out of context of the overall interview. For example, I read all of the data that were coded under the theme 'Importance of Nature'. This process helped me refine the coding scheme and through constant comparison, identify any coding inconsistencies. I refined the coding scheme by collapsing codes, omitting redundancies and non-codes, introducing new codes, and reorganizing themes. I addressed questions about the coding by placing the data back into context and then confirming or refuting my uncertainty. When the 
code did not fit the data, I took one of three steps: I applied an appropriate code, created a new code, or removed the code. Over a period of several months, referring frequently back to my research questions and theoretical framework, I read and re-read through the data and continued to refine and verify my coding scheme. During the focused coding process, I omitted 14 codes, assimilated 8 codes into existing codes, and created 5 new codes. While the first seven iterations were in collaboration with a colleague, successive revisions were completed independently, with oversight and confirmation from Professor Karen A. Roberto (research advisor).

\section{Coding Scheme}

Below is an outline of the final coding scheme, which was organized into four main categories (in connection to the research questions), and consisted of 11 themes and 48 codes.

The women's data were coded across themes throughout each of the four categories.

A) DEFINING NATURE $(\mathrm{n}=34)$

1) Nature Is Right Outside My Door $(\mathrm{n}=32)$

101 General natural elements (air, trees, water, animals)

102 Specific natural elements (river's name, flowers on front deck)

103 Natural systems (weather, storms)

2) Nature Helps Define Who I Am $(\mathrm{n}=13)$

104 Geographic descriptors (county, state, country, rural or city)

B) THE IMPORTANCE OF NATURE IN THE WOMEN'S DAILY LIVES $(\mathrm{n}=34)$

1) Nature is God's Creation ( $\mathrm{n}=26$ )

201 God's creation (no man can create such beauty)

202 We are God's stewards (He's given us beauty, have to keep it that way)

203 Connection to creator (God's presence in nature makes you more spiritual)

204 Cycle/web of life (Life vs. death; renewal and resurrection).

205 Coping (illness/tragedy, daily struggles; God is in control; Bible).

206 Awe (wonderful, impressed, marvel)

207 Gratitude and appreciation

2) Nature is Emotionally \& Intellectually Stimulating $(\mathrm{n}=26)$

208 Joy/Enjoyable

209 Aesthetic pleasure/Beauty

210 Relaxing/Peaceful

211 Energizing/Motivating/Inspirational 
212 Cathartic (relieves stress/anger/discontent)

213 Autonomy/Freedom

214 Enlightenment (alive, interesting, larger than self, broadens world view)

215 Love of nature

216 Active pursuits (walking, gardening, feeding the birds)

217 Passive activities (viewing nature)

3) We Depend on Nature to Survive and Thrive ( $\mathrm{n}=13)$

217 Physical effects of nature (aches/pains, allergies, temperature, comfort)

218 Sustenance/Survival (food, air, water, dependence, health)

C) ENVIRONMENTAL CONCERN $(\mathrm{n}=28)$

1) We Are Destroying Our Natural Resources $(\mathrm{n}=24)$

301 Environmental degradation (harming the environment; using up resources)

302 Clean air, water, and soil

303 Excess waste (physical waste, visible trash)

304 Loss (of local production, human skills, land, habitat)

305 Farming practices (production: pesticides, vaccines, economics)

306 Contamination, disease, invasive species (use of chemicals)

307 Societies motives wrong (money, power, greed, politics)

308 Other's negligence/lack of concern (people don't think or care, litter

309 War (worry about the destruction this is causing for people and the planet

2) Changes to the Atmosphere and Planet $(\mathrm{n}=11)$

310 Global warming

311 Natural disasters

312 Media attention

3) Preservation: Now and for Future Generations $(\mathrm{n}=11)$

313 Preservation/conservation (protect the NE; waste not, want not)

314 Legacy (impact on future generation's health, ability to sustain and enjoy)

D) NATURE TRAJECTORY $(\mathrm{n}=33)$

401 Stable outlook (I have always valued nature the same way)

402 Greater appreciation with age (value nature more as I matured)

403 Increased knowledge/pay more attention

404 I think less about it now

1) My Childhood Influenced How I Feel about Nature $(\mathrm{n}=13)$

405 Childhood activities (what I did as a child: fishing, playing in the fields)

406 Location of childhood home (grew up in rural area/grew up on a farm)

407 Learned about nature from parent (dad was a park ranger, mom recorded weather)

2) Nature Became More Important as I Matured $(\mathrm{n}=10)$

408 Spending time with family outside (recreation, vacations, fond memories)

409 Relocation/Moves (moved to city, back to the country) 
410 Health interference (self or other's)

411 Relationship changed outlook (husband, peer network member, children) 


\section{CHAPTER IV - FINDINGS}

The purpose of this research was to explore rural older women's perceptions of nature. Informed by Place Attachment, Attention Restoration Theory, and guided by a Life Course perspective, in-depth qualitative interviews with 34 older women sought to identify ways in which the women perceived the natural environment, ascertain if their perceptions had changed over the course of their lives and if so, why, and to inquire about their environmental concerns. Over all, the findings suggest that the women viewed nature as a fundamental and meaningful component of their daily lives. Engaging with the natural environment contributed to the women's over all well-being and quality of life. The language used to describe the findings reflects the women's language and not mine. I am aware of the gendered language and ideas the women use to describe their beliefs, but to remain true to the women, I did not make changes to the ways in which they expressed themselves.

As rural residents, the women defined nature by describing what was immediately visible outside their homes; about one-third of the women also defined nature as part of their identity as a citizen of their community, state, or country. Through nature, the women felt a strong connection to God. They believed that nature was God's creation. Some reported that their feelings toward nature had always been strong; for others, it had become stronger over the course of their lives. The women enjoyed daily interactions with nature that resulted in improved mental and emotional energy. One-third of the women also viewed nature as important because it sustained human life. As God's creation and vital for survival, the women voiced concerns about the way fellow citizens and government were abusing natural resources.

The findings are organized and presented by four major categories that address the study's primary research questions: (1) How do older rural women define the natural environment? (2) How do older rural women perceive the importance of the natural environment 
in their daily lives? (3) In what ways are older rural women concerned about global

environmental issues? (4) What influenced the way the women currently think and feel about the natural environment? Four primary themes emerged from the data: nature is right outside my backdoor, nature is God's creation, nature is emotionally and intellectually stimulating, and we are destroying our natural resources.

\section{Defining Nature}

Wright and Lund (2000) define nature as "the biotic and abiotic landscape ecology or bioregion that includes humans as a part of the ecological community" (p. 231). In their definition, abiotic refers to flora and fauna, while biotic refers to topography, geology, geography, and climate. The women in this study identified both abiotic (e.g., vegetation) and biotic elements (e.g., geological elements, climate indicators, geographic locations) as well as wild and domestic animals. Some perceived themselves as a part of nature, going beyond Wright and Lund's definition to include a specific place of residence or sense of identity as part of their definition of nature.

\section{Nature Is Right Outside My Door}

The vast majority of women $(\mathrm{n}=32)$ described nature as natural elements or features either visible from their homes or in their communities. Specifically, the women perceived nature as consisting of the grass, trees, flowers, mountains, forest, rivers, air, soil, water, sun, weather, birds, and other animals. Broadly, the women described the natural environment as "things not man-made," "anything that grows," "the outdoors," and "climate." Describing nature in this manner revealed the women's sense that nature was in their backyards and something they lived with, and in some cases interacted with, on a daily basis. Seventy-five year-old Dale started her day off on her front porch. 
I hear the birds in the morning out here waking up. I am usually sitting here whenever they wake up. I hear them and I enjoy that, and then I watch it get daylight.

Like Dale, several women enjoyed passive activities, such as watching the birds out their windows or viewing a sunset; others actively engaged with nature by walking in the woods, hunting, and gardening. The women placed themselves within their definition of natural environment, and enjoyed being surrounded by nature.

Nature Helps Define Who I Am

For thirteen women, including 10 of the 32 who identified nature as nearby, the definition of natural environment was connected to their sense of identity as a member of their community or citizen of the country. The 13 women defined nature as the place they lived (i.e., their definition of home -- their town, state, or country), and two of them also referred to nature as a resource they felt was being threatened.

Nine of the 13 women defined nature in relation to their identity as a rural resident. They expressed pleasure and pride in relation to their homes and appreciated the abundance, cleanliness, and beauty of nature, and the slow pace of the rural environment. Four women contrasted their rural lifestyles to what they imagined their life would be like if they lived in an urban area or another state. Seventy-six year old Constance moved to a rural community nestled in the mountains of southwest Virginia when she retired 24 years ago.

I have never been a city person. I wouldn't go to live in a big city, forget it. This is so beautiful down here. Really, that's why so many people are coming down, or have come down. It is certainly a lot more peaceful than fighting traffic in a big city, that's not my idea of peace at all. 
Seventy-three year-old Sidney mentioned climate as one of the things she liked best about the rural area where she lived. Sidney compared her life in Virginia to Florida, a state she perceived as having no seasons, "it's green all the time you know? And I love cold weather; I'm a winter baby, and I love cold weather."

Five of the 13 women defined nature as part of their identity as a citizen of the United States. Four of them also mentioned their rural home, but had a broader view of what constituted nature. This perspective elicited a sense of patriotism from two women, including 81-year-old Pete.

I guess I think about the world and what I'm in...the outside, nature, and you know just the place I live in. I am very satisfied with where I am. I just love this country and love this area and love being American.

While Pete and 73-year-old Emily felt a sense of pride, Leanne (age 89) was disappointed and angry at what she perceived was a political climate dominated by big business that did not value or protect the environment.

All these factories, they are built to make money and they give you jobs for a short time and then you are out of here. I don't know, I just ah think it's a poor situation all over. They [big business] are killing it [the environment]. You used to have dreams about America and how it was the number one leader ... now when you get down to the nitty gritty, it's laughable. It's not the number one nation in the world. I don't know which one is, but we certainly can't claim it anymore.

Eighty year-old Zelda also perceived nature as a resource. She viewed herself as a responsible citizen, and immediately brought up her recycling efforts. 
I think it's very important [recycling]. I can't get out and work in the National Forest and that type thing, but I can recycle and take care of that and try to encourage other people to do so, too.

Zelda wanted to be a good steward, but as a resident of a state where resources were plentiful, she found herself wasting water. Although she recycled, she expressed guilt about her misuse of natural resources, and compared the abundance of water in her area with the shortage of water in California and Iraq. Zelda expressed a privilege that led her to feel guilty when she left the tap running.

Summary

Collectively, the women defined the natural environment in a holistic way, including natural elements, events, landscapes, and defined geographic locations. For the majority of women, natural elements were outside their window or part of their local community; their sense of environment was consistently connected to the idea of nature as nearby. Approximately onefourth of the women connected their definition of the natural environment to their sense of identity, suggesting an interconnected and important relationship between the women, their homes, and nature: a relationship that helps inform their sense of self.

\section{The Importance Of Nature In The Women's Daily Lives}

Nature was important to all women and positively influenced their quality of life. They enjoyed nature for spiritual, mental and emotional, and physical reasons. Three themes emerged from the women's responses about the importance of nature in their daily lives: (1) nature is God's creation, (2) nature is emotionally and intellectually stimulating, and (3) we depend on nature to survive and thrive. 


\section{Nature Is God's Creation}

The most common sentiment echoed throughout 26 of the women's narratives was, "Nature is God's creation." The women believed that nature and God were synonymous, and as such, nature represented a context for experiencing the divine. Initially, the interview protocol did not include a direct question about God or spirituality, but after the first few interviews, it became apparent that such issues were important to these women and a specific question about a spiritual connection with nature was added. The interviewer asked 21 women directly if they felt a spiritual connection with nature; 16 responded "yes." Ten other women volunteered (without being asked) God as a reason why nature was important to them. In total, whether prompted or not, 26 women reported a spiritual connection with nature. From their responses about their spiritual connection with nature, two sub-themes emerged: (1) I feel connected with God through nature, and (2) nature helps me cope.

Ifeel connected with God through nature. Nature evoked God's presence, which allowed the women opportunity to connect with God through nature. Nineteen women believed that as God's creation, nature represented the divine world, and as such, interacting with nature brought them closer to their beloved creator. Eight women in this group felt closer to God through nature simply because it was God's creation. Seventy-three year-old Ophelia, who had lived and worked on a farm since birth said, "We've all worked close in the garden and you are close to God when you work in the garden, working the land." Eighty-four year-old Crystal described how she felt when she was outside.

Surely God is in nature and to me that's, I mean being out, people say commune with nature, but to me to be out and see the trees and the birds and the sky and everything, to me that is a spiritual experience. 
Eleven women described nature as God's creation with a sense of awe; it was "miraculous," "beautiful," and "perfect." They enjoyed the peace and quite inherent in their rural environment and loved the diversity and beauty of the flowers, trees, animals and other natural elements or events they believed were created by God. In their minds, God as the creator was present in nature and that inspired a sense of wonder and appreciation. In contrast to man-made structures, nature represented a world that was impossible for humans to create. The women were clear that although people can influence or alter nature, it was impossible for a human to be the architect of such a beautiful world. Seventy-three year-old Emily wondered how anyone could contemplate nature and doubt God's existence. "Like those trees out there, how could anyone look at those and doubt there's a God? Man can't do that. Definitely not, not for me." Fatima (age 71) offered a similar sentiment and adamantly insisted that no man could create such perfection or beauty.

I mean you walk out and you see how pretty the trees are getting, how pretty the flowers and the grass and all that God has made. I mean just look around you, no man can make what you can walk out there on the porch and look out and see. You know, no man could make that.

It was clear to all of the women that nature was God's domain, and they valued it more than man-made structures. Eighty-one year-old Rhonda felt deeply connected to God when viewing a river from her back deck and said, "They (natural elements) are much more important (than mad-made things). In my heart I love nature... it brings me closer to God than other kinds of objects."

The women's belief that nature is God's creation was reinforced each Spring when the trees and flowers would bloom, or every time they experienced a natural occurrence, beyond 
man's control. Zelda (age 80) was in awe of nature because it was alive and represented the mystery of life, growth, and change.

I am always so amazed when the bulbs come up every year and the trees start blooming. How do they know this? You know I think it's so marvelous.

Also amazed by God's work, 86-year-old Violet gave an example of a time she felt particularly moved by nature.

I think nature makes you more spiritual. There are so many beautiful things to see. We had a sunset a couple of years ago all the way across (the sky). I had never seen blues that color. It was the most beautiful thing I have ever seen. It was very emotional.

Four women expressed a deeper understanding of the natural world, and described a cycle of life. The women explained that nature was an interconnected system governed by God's laws. Eighty-five year-old Imogene, who had gardened for years, was amazed that God created such an efficient system.

Are you aware that there are certain plants that are like a drug to the soil? I mean a good drug to the soil -- their roots create or solve some problems that the dirt can have...like spoiled tomatoes. If you plant marigold around it, its roots are like a drug that takes care of whatever is disturbing that ground. That's the Lord's work you know...I'm impressed with the way the Lord takes care of us.

Nature Helps Me Cope. The fundamental belief that nature is God's creation led seven women to the observation that God was in control of the universe. The women turned to God for explanations, comfort, and support. The women differed to God for concrete answers to unknown questions and looked to God for strength and guidance in specific situations. Hilda (age 80) embraced the bible's teachings and believed she would be received in heaven. Her 
explanation about the importance of nature illustrates how nature and faith are intimately connected.

When you get up of the morning and you see that beautiful sunrise and you get you a good ole drink of water, you thank the Lord for it. You realize that he's given you this and He keeps on giving to us and supplying our needs and everything. He's the water of life. He told us if we believe in him we would have eternal life and go be with him (after death), and that's a better place than what we have here that's for sure, and I thank the Lord for that.

Hilda's belief in God and the bible supported a gracious outlook on life, which provided her with a positive foundation for going about her daily life, and helped her come to terms with dying, which is a source of anxiety or fear for some older adults.

While Hilda forecasted into the future in a personal way when referring to the bible and her faith, Dale (age 75) speculated about the health of the planet. Dale's acceptance of biblical teachings allowed her to stave off worry or concern about the planet's health, thus avoiding negative emotions.

The Bible says that the earth will not be destroyed until the Good Lord comes. So then what we do here, if anything is missing then people done it, but that's still not going to destroy things. You might suffer from this, that and the other, but I don't think it will destroy anything. That's the way I feel about it though. That's what the Bible says. Despite the difference in what prompted these two women to worry, both trusted the word of the Bible as truth, which gave them peace of mind.

Personal adversity fueled a strong relationship with God for two other women. Josylen and Gail explained that their faith is what got them through previous negative life experiences. 
Josylen (age 83) emphasized the importance of her relationship with God and said she could not have made it through her health episodes without Him. She lived near a state park the majority of her life and loved the natural surroundings; she felt close to God through nature. When her health began to decline (i.e., heart, knee, and back surgery) she moved closer to a city where she could have better access to health care facilities. She missed being so close to nature, but told the interviewer that part of what helped her adjust to her new surroundings was her back room. She arranged the space so she could sit comfortably and look out a window across the highway and onto a mountain range.

I love to be where I can sit and look at nature; it relaxes me, and I feel closer to God. I would still live in the country if I had my health back like it used to be because I used to drive. But here I sit back there in that room and look at the hills and across on the other side the interstate [and get satisfaction out of that].

Gail (age 77) also relied on God to help her cope, and pointed to events in her past that strengthened both her relationship to God and her appreciation for nature. Gail grew up on a farm, but moved to Baltimore as a young woman. While she was there, her husband was shot and killed by the police. She relied on God to help her cope with the trauma of her husband's death, but missed the familiarity and abundance of nature in Southwest Virginia. She tried to enjoy the natural spaces in Baltimore, but explained that it just was not the same. She moved back to the rural environment with her four young children shortly after her husband died, and was glad she had. Later in life she experienced health problems, which further enhanced her relationship with God and the connection she felt with God through nature.

Three other women referred to their belief that God was in control or "sets things in motion" as explanation for natural occurrences, such as the weather and natural disasters. 
Allowing God control over the universe helped the women reconcile the cause of trauma or natural disasters.

\section{Nature Is Emotionally and Intellectually Stimulating}

The women received emotional and intellectual stimulation through their relationship

with nature. When they were asked why nature was important to them, 26 women responded with explanations centered on their psychological well-being. Four sub-themes evolved from their responses: (1) nature is relaxing; (2) nature is energizing; (3) nature is liberating, and (4) I like to learn about nature. The first three sub-themes constitute emotional stimulation while the fourth represents intellectual stimulation.

Nature is relaxing. The majority of women $(\mathrm{n}=20)$ loved nature because it brought them pleasure and made them feel relaxed and peaceful. When defining nature, they spoke about how beautiful nature was and referred to nearby natural elements, such as the trees and flowers in their back yards, or the mountains in clear view from their homes. Eighty-two year-old Udele, who grew flowers every year, lived in a small house with a yard. She, like most women in this sample, had easy access to what she defined as nature, and cherished this aspect of her life.

If I had to be in an apartment without being able to get outside, I would lose my mind... It's peaceful. It's just something I have to have.

Rhonda (age 81) also felt strongly about her need for nature, and said she would do anything necessary to stay in her home for as long as possible. She had always lived in the same small town that was nestled beside a major river; viewing that river from the back of her home was a meaningful pastime she did not want to lose. 
[Nature] is all the things that God created. They are much more beautiful than man-made things and much more important. Tall buildings and that type thing, I am not interested in city life or anything. I like the country, especially the river I can see from my small home. Interacting with nature was also a cathartic experience for the women. Eighty-four yearold Wanetta spent most of her adult life living in a home with a greenhouse and a large back yard where she grew and sold roses.

When I lived on West Main and I was upset and troubled, I was out there digging in the dirt and it helped. I love being outside, and I don't have that here, but what little space I've got I try to do something with it.

Wanetta was also an artist and painted watercolors of nature scenes, such as birds, flowers and gardens. After moving to a smaller residence that did not have a garden, Wanetta spent more time painting and when she walked by her local museum, she would weed their flowers beds.

Nature is energizing. For six women, nature was a motivating force. The reasons for the emotional boost varied from the effects of weather to the presence of diverse flora and fauna. Nadia, who at age 71 spent time chauffeuring her grandchildren and neighbors to activities and appointments, explained that in her later years the weather was increasingly affecting her energy level and mood.

I am so influenced by sunny days. If it's dark and dreary, sometimes I'll just sit around and not do much of anything, maybe read or watch a little television, but I don't feel energized to do anything. So, you know like I said if the sun is shining, I feel better when the weather is nice.

She told the interviewer that when she was younger there were other factors influencing her life, such as work and raising a family, which distracted her from noticing the connection 
between her energy level and the weather. Now, having more free time and the flexibility to do what she feels like doing has allowed her the freedom to notice, and pay attention to her overall energy level and the factors that influence it.

Two women, including 71-year-old Fatima, suggested life would be depressing without the presence of nature.

We have got the trees and grass and all this that you see and as pretty as everything is, what would life be without it? If you go out and everything is bleak, you know how it looks in the winter, everything dead and all of that, if it was like that all the time? Their underlying sense of excitement heightened as the women described how nature motivated them and boosted their energy level.

Nature is liberating. Four women said they loved nature because it gave them a sense of freedom and independence. For three of these women, nature was associated with their ability to get out into the open, away from their man-made surroundings. A compromised sense of independence is often a feared outcome of the aging process, but these women suggested that access to the natural environment enhanced their sense of independence and provided a buffer against feelings of confinement. Eighty-nine year-old Leanne was in a rehabilitation center when she was interviewed, but said, "even in a wheelchair I could go outside and see the flowers and things." Seventy-five year old Melissa experienced a sense of freedom when viewing wildlife in the open field behind her home, "You just see things like rabbits and turkeys; the field will be full of turkeys. I just like it, and it makes you feel like you are not closed in.”

The physical experience of nature gave 73-year-old Emily a sense of freedom, which she connected with feelings of patriotism and gratitude.

Every morning I can get up and look out and see the beauties of nature, breathe the fresh 
air and know that we are free to do it. We have the freedom here to do as we please, to see, to look, to feel, which other nations don't have. We take it for granted, but we have the freedom to look out on everything that we enjoy. I guess that's maybe, maybe that's not a good way to express it, but to me it's being able to do it. To be able to see and hear and feel you know.

I like to learn about nature. Four women's explanations of why nature was important to them went beyond positive emotional stimulation and spanned into the intellectual realm. The importance of nature was embedded in the context of mental stimulation; they found nature interesting and pursued learning about, and interacting with, the natural world. Eighty-three year old Odessa kept flower-beds and hanging potted plants on her patio and enjoyed nurturing her local bird population.

I have two bird feeders and a bird-bath, and I enjoy birds so I buy books; I am interested in their behavior. It's interesting to watch them bathe in the bird bath, and I was so interested in what they prefer in the way of feed, of the seeds and so forth.

In contrast to Odessa, Patsy (age 86) was not interested in animals, and had quit growing flowers and gardening because of health-related issues, but explained that she found nature interesting and was inspired to travel so she could see, first hand, nature's diverse beauty. I have always loved to travel and see you know beautiful things around... it just broadens your outlook on life. As long as I can remember I always wanted to go places and see things that were in the geography books and things like that.

Seventy-four year-old Simone was engaged in a life-long nature-related pursuit. She was the family weather-woman, carrying on a tradition started by her mother of writing down the temperature and general weather patterns every day. 
I love to study the atmosphere you know... when I get up in the morning, I like to study the atmospheric pressure and the relative humidity and all of that, and then I can go about my business that day because I know what it's gonna be. My mother did the same thing, and when my mother died on her calendar that day in the kitchen she put the morning temperature you know and the forecast for the day, and I like that you know.

\section{We Depend on Nature to Survive and Thrive}

The third major theme reflected a very practical view of nature and the influence it had not only in the women's daily lives, but also for humankind as a whole. Thirteen women viewed nature as a set of resources fundamental for the human race to survive and thrive. They defined nature as elements that support existence (e.g., food, air, water, and land), and recognized that without nature, human life would cease to continue. Eleven of the 13 women perceived nature as God's creation, but only 80-year-old Hilda made a direct connection between God and survival.

I just know that God created everything and then He made it so it supplies us with our air and water, food, and the trees, and we are burning them all up out west now. All kinds of things that God made, and He keeps it going. So it's very important; it's something that we have to have to live.

Hilda was grateful to God and added, "If we didn't have this earth God made for us and keep it going, we sure would be in a fix."

The other women who believed nature was God's creation kept the idea of survival and God separate, and voiced concern about human activities negatively influencing natural resources. For example, Jodi (age 81), who used to farm, was skeptical about pollution from chemicals used as household items and in agriculture.

It bothers me the way we use pesticides and Clorox, for instance, that goes into the 
ground. I think there have been studies on pesticides and sprays and I worry about that. And, we used to have cattle on the farm and now you vaccinate them for this and that. Well, you think that goes into the meat we eat; they give them pills to make them grow faster.

Economics was a concern for one of the five women who considered the influence of weather on her ability to thrive. Noel (age 75) worried about the rising costs of goods and services (e.g., groceries and utilities) in the wake of natural disasters, such as hurricanes and tornados. Other women who noted weather, such as 91-year-old Barbara, described the daily task of adjusting to the outdoors.

I have got to endure it or stand it or live with it or deal with it, or I've got to make some sort of adjustment to it. If it's cold, I've got to get a coat; if it's hot, I've got to take off a coat. If it's raining, I've got to get something to keep me dry if I want be dry or if I just want to get rained on, I leave the rain coat at home, but you have to deal with it.

Barbara also contemplated others' complaints of aches and pains in connection to the weather, but did not identify this as a problem for her, nor did any of the other women in this study.

\section{Summary}

The natural environment played an important role in the women's daily lives. First, the women believed nature was created by God and represented a divine presence in this world. When directly interacting with nature, the women felt closer to, and in some cases, supported by God. The women compared nature to man-made environments with a sense of pride, and described nature as a context that nurtured, enhanced, or reinforced the women's intimate and positive relationship with God, thus bolstering their overall well-being. For some women, their relationship with God helped them face and overcome adversity, while for others, God's 
presence and perceived control of the universe helped explain natural disasters or other phenomenon they felt were out of the realm of human control (e.g., death, seasons, plant growth). The natural environment was symbolic of God and provided a context for them to experience their spirituality.

Second, the natural environment elicited or enhanced positive feelings, warded off or prevented negative feelings, and in some cases, provided the women with opportunities to engage their intellect by exploring or nurturing organic elements (e.g., flowers, birds).The majority of women described feeling relaxed in nature, while a small number said nature boosted their energy or made them feel free. Positive emotional stimulation was either the result of, or the motivation for, interacting with nature and several women enjoyed passive activities, such as watching the sunset. Some women engaged in learning about and experiencing nature through direct and ongoing interaction. The women's emotional satisfaction and intellectual engagement positively influenced their psychological well-being.

Finally, nature was important as a basic necessity for life, vital for survival, and influential on how well the human race could thrive. While the previous two themes were rooted in a psychological paradigm, this theme revolved around biological imperatives. The women perceived the natural environment as natural resources or as a system that influenced human survival, health, and comfort. As a life-support system that influenced human health, the women realized the environment was subject to harm by human activity.

\section{Environmental Concerns}

Twenty-eight women expressed high levels of concern about the natural environment. Although questioned in relationship to the global environment, the women named both local and global concerns, such as pollution (e.g., local landfills), and natural disasters (e.g., earthquakes, 
hurricanes). The most common environmental concerns were related to the outcomes of population growth and the production and consumption of goods. Three themes emerged from data: (1) we are destroying our natural resources, (2) changes to the atmosphere and planet, and (3) preservation for future generations.

We Are Destroying Our Natural Resources

The most prominent concern of the women was for the perceived abuse of the planet's natural resources. Twenty-four women believed society was inflicting too much damage on to nature, which put the quantity and quality of the earth's natural resources in jeopardy. The women criticized both citizens and politicians for the situation.

Pollution. Twenty women declared pollution, in various forms, their number one concern. The most common offense was related to either the type, or amount of garbage currently produced and shipped to landfills. Several women, like 80-year-old Zelda, were angry about this issue.

Look at our landfills that are just being over run. What's going to happen when they dig up and find all of this plastic? They will say, 'What did these people do?' 'What is this plastic?" Because it will never go away.

Like other women living in communities with recycling facilities, Zelda recycled what she could and viewed her efforts as doing her part to help minimize her ecological impact. But, not all of the women who wanted to recycle could. The recycling bins that Nadia (age 71) used were removed due to misuse. Nadia was angry that people could be so irresponsible, and frustrated at the situation.

Now everything just goes in the landfill, and I hate it. I hate the paper towels, the paper plates, the cups, everything that I see not disintegrating, like the Styrofoam. We are 
drowning in our own waste and there is no such thing as throw away. It's going to come back to haunt us.

Nadia, like five of the other women willing to do more to help prevent excess waste to landfills, felt helpless and unsure about what more to do. For example, 75-year-old Melissa wanted to take action with respect to the presence three junkyards near her home.

There are miles of it [junkyards]. I tell my husband, these rusty old cars drain into the dirt; the oil leaks out of them if there's any in it and the rust goes down into the water system and then you drink the water. It may be just my opinion, but I don't think it's good; I think something needs to be done about it, but I just don't know who to call... There's a lot of people around here have cancer now, and maybe I am wrong, I hope I am, but it's coming from somewhere.

Suspicious of the negative health effects of pollution, four women voiced concern about pollution in the food supply, or pollution created by industry. Both 73-year-old Sidney and 81year-old Jodi worried about the health outcomes of crop and animal production methods that used pesticides and vaccinations. Sidney also thought about the risks of importing foods from outside the United States. She was among three women who questioned the virtues of the current political climate in relationship to protecting the natural environment.

What I have noticed lately is the food. I get apples, strawberries, cantaloupe, and other foods from out of the country. If we buy from them to feed ourselves, why don't we grow it? Why would we take a chance of using their fertilizer, which their do's and don'ts are different from our do's and don'ts.

People and Politics. Sixteen women criticized government and fellow citizens for what they perceived as negligence toward environmental protection. The women were angry, annoyed, 
and disappointed with how little they perceived other's valued nature. In their criticism, three women took a broad view of the political climate, and complained about what society had lost in the process of coming to value economic gain over conservation. Most of the women were young children during the depression, or born shortly there after, and were taught from the beginning to be resourceful and conserve. The women had seen the country move through adversity and took pride in what they perceived was now lost to a society motivated by greed. From her perspective, 89-year-old Leanne viewed compassion as lost from the public arena.

The whole world is too involved in the wrong endeavors. It all boils down to money and power and it ought'n to be that way. It ought to be where it's people helping people all over the world. That's the way it should be.

For Sidney (age 73) the current economic system valued technology too heavily, which she believed contributed to a loss of human skills (e.g., making leather, growing your own vegetables). She was disappointed that because of the lost skills, individuals were now dependent on, and valued global markets. At the heart of her concern was how little the global economic system valued natural resources. Sidney also mentioned that the environmental destruction caused by wars troubled her. Two other women perceived war as destructive: Constance (age 76) worried about the effects of chemical warfare and Gail (age 77) felt war went against God's will. Gail also worried about the loss of farmland, mountains, and forests to development, fires, and the forest industry.

I think of all the mountains and everything that's being destroyed and all the trees they are cutting down and all the animals that are you know dying because of all of that. I am extremely concerned about it, but there's not really anything I can do I don't guess. 
It was common for the women to feel helpless to effect change. They simply wished people would be more concerned and take responsibility toward protecting it.

\section{Changes to the Atmosphere and Planet}

Eleven women identified global warming, storms (e.g., hurricanes, tornadoes), earthquakes, and forest fires (man-made and naturally occurring) as concerns. Knowledge and religious convictions influenced their interpretation of the role humans played in relationship to these phenomena. Eight women were worried specifically about global warming. Generally, they accepted the message they received through media that humans were influencing the atmosphere and storm activity, but they were tentative about their knowledge, calling it mysterious, or a scientific matter they felt they should know more about. Just three women were confident in their opinions about global warming: Simone and Nadia (age 74 and 71, respectively) were both certain that humans were responsible for changes to the earth's atmosphere, but Zelda doubted the role of humans and instead, put God in control.

I think about all these disasters that we have, the natural disasters, and you try to reconcile to something and the only thing I can think of is that God set it in motion. He set the law of gravity in motion. Well, you can't just all of a sudden take gravity away, and if that's what's happening in the atmosphere and we have the storms, it's horrible, but what are you going to do?

Most women felt helpless and wondered what they could do to make positive contributions toward improving the situation. Only 80-year-old Alysia was actively seeking information (e.g., planned to see a movie about global warming) to help her better understand global warming and how she may help. 
The women viewed their global concerns as outside the realm of their daily lives. A few women expressed empathy for people caught in natural disasters, but they did not perceive any direct personal impacts. The exception was 75-year-old Noel, who lived on a fixed income and worried about making ends meet.

I was just thinking about this global warming and how all these earthquakes and tornados are affecting our standards of life. The price of things have gone up; I think that the prices of food, and I noticed gasoline and so forth that has all gone up because of the natural disasters. Therefore it affects your billfold.

\section{Preservation: Now and for Future Generations}

Eleven women voiced a desire to better protect and preserve the natural environment. The general consensus was that current society abused nature by squandering natural resources and producing too much waste in the wake of production and consumption. Seven women grew up during the depression (they were aged 3-8 at the beginning of the depression and 13-18 at the end), including 80-year-old Zelda who reflected on her childhood.

I wonder sometimes growing up during the Depression when things were so scarce and you had to make things last and you had to make things do; not that I was thinking about it as the total environment but I think when you have grown up through that then you begin to relate that to a broader, wider idea. It's almost like a continuation you know, being careful, don't waste.

Three women connected a conservative outlook to their faith. The women believed that nature was God's gift and meant for humankind to nurture and protect it. The general sense, as articulated by 71 -year-old Nadia, was that humankind was failing the duty of protecting and caring for God's creation. 
God made this world and He gave it to us, our stewardship is that we take care of it for future generations; our grandchildren and great grandchildren are not going to have a decent place to live if we don't. In fact, it may already be too late for some parts of it, the streams. I used the swim over here in this creek, but I wouldn't go in that creek now.

Nadia and four other women worried about the legacy they were leaving future generations. Crystal (age 84) said, "this thing of, you know, just building on every little inch of ground and taking mountains, what are children who come after us going to have?" The women who worried about their legacy were college educated, which may have influenced their ways of thinking about the environment. Generally, all women in this group were concerned about protecting the natural environment through conservation (use, but do not abuse) and preservation (maintain and nurture).

\section{Summary}

The world around these women had changed, but the value they placed on nature had not. They were concerned about environmental issues and attributed their worry to four causes. The increase in the amount of natural resources being consumed, methods used to produce consumables, an increase in industry and infrastructure (development), and a greater amount of media attention.

Most women had a general disposition toward conservation and their number one concern involved how wasteful and negligent they perceived current society to be. The women were most commonly angry or annoyed by pollutants that were damaging the natural environment (excess garbage going to landfills, people littering). They were disappointed that politicians and citizens did not value nature enough to protect or care for it. Instead, they viewed 
politicians as allowing industry to destroy nature, and citizens irresponsible for neglecting to care for a public good.

The issue of control lay at the heart of the women's belief about whether or not they could make a difference. In relationship to waste, most women tried to "do their part" by recycling, but a general sense of helplessness loomed over concern about natural disasters. The women named global warming most frequently, and most connected natural disasters with global warming, but they were tentative about how well they understood the phenomena, and unsure about their ability to have a positive influence.

Six women, who were not concerned about the global environment, simply did not pay attention or did not care to know. Dale (age 75) referred to her religious belief that the earth would not be destroyed until the Lord came, as an explanation for her lack of concern. All six women valued nature, but did not perceive environmental problems as close enough to home to warrant their attention.

\section{Nature Trajectory}

The women's current thoughts and feelings about nature provided a snapshot along their nature trajectory. To understand how the woman came to value nature, it was important to explore their past experiences and inquire about the factors or events they perceived may have influenced their trajectory.

Slightly more than half the women $(n=18)$ reported a change in their nature trajectory, explaining the change in one of three ways: a greater appreciation for nature over time $(n=11)$; an increased amount of attention $(n=5)$; or a decreased amount of attention $(n=2)$. The other 15 women reported stable positive perspectives toward nature; one woman was not asked. Of the 33 women who responded to the question about change, one-half offered insights into their 
perceptions of what influenced their trajectory. Two themes emerged: (1) my childhood influenced how I feel about nature, and (2) nature became more important as I matured.

\section{My Childhood Influenced How I Feel about Nature}

Thirteen women recalled childhood experiences when reflecting on their nature trajectory. The women had fond memories of where they grew up (e.g., a farm, rural area, country, mountains), the kinds of activities or events they experienced as children (e.g., gardening, swimming), and the people they felt influenced how they valued nature today (e.g., role models). Eighty-four year-old Wanetta named all three early influences.

I feel like I grew up with it from the day I was born [nature]. I was raised on a farm and learned to, you know, I worked in the fields with my dad. So I have always loved anything that was growing.

Gail (age 77) also grew up on a farm. Walking in the woods with her dad had a positive influence on her life. Role models in childhood were consistently parents, and for 74-year-old Simone, adopting her mother's habit of recording weather statistics every day provided her a role to play with her extended family. As the family weather person, Simone would get calls from her nephews when they were little, asking her "Auntie, what's it gong to be tomorrow?" Now adults, she laughed and said they still called asking the same question.

The kinds of activities and events the women described as influential varied from naming their favorite swimming hole to the influence of growing up during the depression. The Catholic Church helped shape 73-year-old Sidney's outlook on nature.

I was raised Catholic, and I was in Catholic boarding school for years, and you just have to respect everything [nature]. You don't take without harming. It's like, you know, if you 
take a pill to heal something, you destroy something else in the process, you just don't know it.

Nature trajectories for women in this group were both stable, and changing. The common thread was a foundation of pleasure and respect that was associated with nature and instilled early in women's lives. The difference between the stable and change women lay in their adult experiences. Most of the women who reported change in their trajectory named later life events or influences that either increased their appreciation for nature, or the amount of attention they gave to environmental problems.

\section{Nature Became More Important as I Matured}

Post childhood, as the women set out to create their own lives, their nature trajectory changed. Eleven women developed a greater appreciation for nature during adulthood, and five began to pay more attention.

Nature's influence on the women. The women named new roles in early adulthood, or simply a maturing that influenced a change in the way they perceived nature to influence their daily lives. In later life, the change was related to the women's relationship with God.

Four women experienced a transition in their nature trajectory when they got married, moved, or became a parent. Those milestones marked a clear shift in the women's appreciation for nature. As a result of getting married, Melissa and Sidney (age 75 and 73 respectively) moved to rural areas and began working outdoors (e.g., caring for cattle, picking apples). Sidney was the woman who spent her late childhood in a Catholic boarding school, where she developed an intellectual understanding of nature. She moved to West Virginia from Florida after she got married, and said it was like an awakening. She recalled her honeymoon at a sate park where her husband introduced her to the names of trees and birds. As older adults, both women voiced a 
preference for being outside and Sidney said, "I couldn't live without it".

Four other women took nature for granted when they were young, but grew to appreciate it more as they moved into adulthood and discovered what they valued in life. They reflected on this shift as a normal developmental process that involved gradually honing their priorities in life as they grew to better understand themselves and the world around them. Along the way from early adulthood to later life, five women spent time outdoors with their families (e.g., summer vacations at a lake), which strengthened their positive feelings toward nature and created fond memories for the women to reflect on and enjoy.

As the women moved into their later years, spirituality began to take on a greater level of importance in the women's daily lives, and four women experienced a greater appreciation for nature because they viewed it as God's creation. Spending time in nature helped them feel supported by, and closer to God. Changes in health status increased the importance of God and nature for two women, including 83-year-old Josylen. She credited God for helping her through a major heart attack, back and knee surgery, and rearranged her new home in order to feel closer to God. Josylen had moved from her old home next to a state park to a small city to be near health care providers, and to compensate for being so far away from nature, she created a room in her home where she could sit and look out the window at a view of the mountains. With gratitude, Josylen took satisfaction from viewing nature. Two other women who felt their connection to God grow in their later years referred to this change as normal. As Crystal (age 84) said, "I think as you grow older those things come. When you are younger, you don't think about it as much."

The women's influence on nature. Five women attributed a shift in their nature trajectory to increased knowledge about or attention to environmental problems. All of the other women took a personal perspective with their environmental trajectory, reflecting on how and why 
nature was important to them, but these women were concerned about how they may be negatively influencing nature. Their level of concern about environmental problems had recently increased and they were paying attention to information from peers and the media. For example, Imogene (age 85) had recently moved to a retirement community and began interacting with a retired environmental biology professor who she described as "enlightening" her about environmental issues.

He is fascinating. He has made me aware that Americans waste about 30 percent of our product on just waste because we don't preserve. I didn't realize I was wasting things. I was brought up very strongly you know, I mean if I don't eat I think of a poor child that's starving or something. So, I had thought about it, but I never got very conscious about it. Four other women experienced heightened levels of attention and credited increased media coverage for their understanding of environmental issues. These women had always perceived nature as important, but viewed the world around them as changing in ways that were harmful to the environment. They were paying attention, and interested in learning more about the problems and what they could do to have a positive impact.

\section{Summary}

For about one-half of the women, the environment gained importance over the course of their lives. Early childhood was an important time to establish an appreciation for nature. The most common positive influence was the location of their childhood home, which provided exposure to nature-based activities the women continued to enjoy well into their adult lives. Parents were a positive influence and the women had fond memories of the times they spent with their parents either enjoying, or learning about nature. Two women mentioned the influence of culture on their upbringing. Within the context of their educational environments, they noted the 
persistence of the overall message: preserve, don't waste, and respect nature. The influence of context speaks to the importance of culture when considering environmental ethics.

As the women moved into their adult lives, transitions into marriage, parenthood, and new homes changed the women's appreciation for nature. While some women noted events as turning points along their trajectory, other women noted a more gradual change, and believed their greater appreciation for nature grew as a result of maturing. The women experienced a plateau between early and late adulthood; as they entered into the later years of their lives, several women noted another change, with nature becoming even more important because of the connection the women felt between God and nature.

A few women experienced a change in their level of concern over the state of the natural environment. These women thought of others and how their current lifestyle influenced nature in a negative way. Their information was derived from media and peers, and there was a general sense of displeasure that they could not do anything to ameliorate the situation. Finally, two women stated they thought less about nature than they had when they were younger: Katy (age 72) had a narrow perception of nature, naming just household pets as what constituted nature, while 91-year-old Barbara was distracted during the interview. 


\section{CHAPTER V - DISCUSSION AND IMPLICATIONS}

In this qualitative study of 34 older women living in rural southwest Virginia I explored how older women perceived and valued the natural environment, what they thought influenced the development of their perceptions, how their outlook may have changed over the course of their lives, and any concerns they had about the current condition of the natural environment. Informed by Place Attachment and Attention Restoration Theory, and guided by a Life Course perspective, two major findings emerged from the women's narratives: the women valued nature for spiritual and psychological reasons, and nature was suffering as a result of a wasteful and destructive economic paradigm.

In this chapter, I first discuss issues related to the major findings. The first two sections, Nature, Spirituality and Place and Nature's Psychological Benefits, speak to the importance of nature in the women's daily lives. In the third section, The Nature Trajectory, I discuss the findings from a life course perspective. Although this section stands alone, life course influences related to other research questions are addressed in the appropriate section. The fourth section, Environmental Destruction, explores the findings related to the women's concerns, and the fifth section, Accepting Responsibility: Sustainability and Control, highlights how the women responded to perceived environmental concerns. I conclude the chapter with a discussion of the study limitations, suggestions for future research, and practice recommendations.

\section{Nature, Spirituality and Place}

The importance of religion and faith in rural America is well documented (Behringer \& Friedell, 2006; Coyne, Demian-Popescu, \& Friend, 2006). Religious traditions are carefully passed on from one generation to the next, and in times of hardship, faith in God is an important source of emotional support. For most women in this study, nature and God were synonymous. Nature evoked a divine presence and served as a context for the women to experience their 
spirituality. When engaged with nature, either actively or passively, the women felt close, connected, and supported by God (Frederickson \& Anderson, 1999; Underwood, 1999).

God was a central force in the women's lives and defining nature as God's creation reflected a strong emotional bond between the women and nature (Williams, 2008; Williams \& Vaske, 2003). Their sense of nature as composed of nearby elements and systems they experienced when they walked out their front door placed the women's homes in the heart of a context that supported and reinforced their religious beliefs. This perspective on nature represents an individual view and speaks to the women's relationship and sense of intimacy with their divine creator. Nature was highly valued because it represented God and provided the women with an immediately accessible place to experience their spirituality.

About one-third of the women who expressed a personal relationship with God through nature also articulated a broader view of nature by describing it in connection with their sense of identity as a member of their community, or citizen of the country. Individuals become attached to group identities through social links and meaningful connections from which a sense of place develops and takes on significant meaning in their lives (Williams, 2008; Williams \& Vaske, 2003). When the women in this study identified themselves as rural residents, they expressed pride about their values, which they shared with others as part of their rural culture (e.g., religion, family cohesion, friendship, health, and integrity) (Behringer \& Friedell, 2006; Coyne, Demian-Popescu, \& Friend, 2006). As is common among older adults, the women often expressed a desire to remain living in their own home and current community for as long as possible. Previous research has demonstrated that place identity increases a sense of belonging to one's community (Vaske \& Kobrin, 2001). The women's sense of identity supports that finding; they were connected to living in a rural environment, which they experienced as God's creation. 
They embraced life in rural Virginia, and some identified with the rolling mountains, wildlife, and clean air.

\section{Nature's Psychological Benefits}

Engaging with the natural environment had a positive influence on the women's mental and emotional energy as the women consistently mentioned the pleasure they received from their interactions with nature (Frumkin, 2001, 2003; Hartig et al. 1991; Moore, 1981; Ulrich, 1984). After spending time with nature the women often felt relaxed, rejuvenated, free, and intellectually stimulated - all hallmarks of a restorative environment (Kaplan, 1995). As noted in previous research, the women frequently discussed their spirituality in connection with components of a restorative environment (Jansen \& von Sadovszky, 2004). Attention Restoration Theory (ART) posits four components of a restorative environment, three of which the women's narratives support: fascination, extent, and compatibility.

\section{Fascination}

The first component of a restorative environment, fascination, refers to an environment that evokes an involuntary natural curiosity, or sense of awe. Nature elicited fascination based on the women's faith. Not only was nature God's creation, He also controlled life on the planet and was responsible for continued growth. Based on their beliefs, and their appreciation for nature from an aesthetic point of view, the women stood in awe the natural environment around them. Extent

The second component of a restorative environment requires individuals to feel as if they are in a completely different world. Extent was evident in the women's narratives when they contrasted nature to the man-made world (built environment). Nature was more beautiful and more valuable because it was created by God, and it could also never be replicated by humans. A 
few women, who expressed feeling a sense of freedom in nature, may have been experiencing liberation from their human created surroundings.

\section{Compatibility}

While the first two restoration components are about feelings, the third, compatibility, refers to function. It describes an environment that easily supports the person's desired activity. The women were not asked directly about their activities, but they volunteered evidence of compatibility. Among other activities, the women spoke about how much they loved gardening, walking, and watching and feeding the birds. As a source of emotional support, compatibility between the women and nature was an important concept.

As declines in the women's health resulted in changes in their functional abilities, they could no longer engage in nature-related activities they had always enjoyed (e.g., gardening). Most of the women exercised a sense of agency and took action. They either changed the activity or the environment, or both, to create a compatible situation. Over time, they let go of their desire to engage in the previously favored activity and found satisfaction with the new one. The outcome was a greater appreciation for nature interactions. This finding supports previous research suggesting that older adults coping with disease symptoms benefit more from time spent in nature (Garst, 2005; Ottosson, \& Grahn, 2005). The positive psychological benefits of spending time in nature interact with, and have a positive influence on physiological functioning (e.g. decreased heart rate, lowered blood pressure), which results in an overall improvement in well being.

Finally, in contrast to the work of Italian researchers Scopelliti and Guiliani (2005), who found being away and compatibility consistent descriptors of a restorative environment, I found that rural older women did not articulate an escape from their daily lives (being away). The 
theoretical concept being away suggests a break from it all, as if to get away from stress, but this group of women lived in their restorative environment and access to it was seamless. Nature was too entrenched in their daily lives for them to perceive themselves as being away and none of the women suggested a desire or need to get away. Attention restoration theory developed without consideration to age or the other issues of diversity, such as geographic location or class. This finding speaks to the importance of accounting for, and exploring the diverse influences that shape individual lives.

\section{The Nature Trajectory}

Bringing a life course perspective to the research provided insight into how the women's relationship with nature developed and changed over time, and the influences affecting that relationship. The women followed a nature trajectory, or pathway, to their current perceptions of nature. The profound influence of geographic location laid a strong and positive foundation for the women's nature trajectory. Most women grew up living close to nature (e.g., lived and worked on farms, or grew up in the country), and their retrospective accounts of their childhood experiences were positive. The women recalled activities they enjoyed and role models they loved, who passed along their values and sense of care, concern, and knowledge about the natural environment. Once established, the positive emotional bond between them and the natural environment remained throughout their lives. For about one-half of the women, that bond strengthened as nature became more important over the course of their lives. Major transitions over the life course, such as becoming a parent, getting married, or moving, or more subtle turning points along the women's path toward maturity, marked new levels of attention to, and appreciation for nature. Later in life, the women noted another shift along their trajectory as nature and God became more important in their daily lives. 
An increasingly important aspect of their lives, the way in which women came to value nature more in their later years describes a late life developmental shift referred to as Gerotranscedence (Tornstam, 2009). Gerotranscedence represents a final life stage toward maturation and wisdom. It occurs with a shift in focus away from a materialistic and rational worldview toward a more cosmic and transcendental one (Gatz \& Zarit, 1999; Tornstam, 2009). Individuals who move through this process become less focused on the self and more selective about how they spend their energy. The process has been referred to as turning inward, when there is a great need for solitary meditation. The outcomes may include redefinitions of the self and relationships with others, a new understanding of existential questions, and a new found level of life satisfaction (Tornstam, 2009). For the few women in this study who appeared to be involved in this developmental process, nature provided the ideal context to experience the shift in priorities. They had established a strong emotional bond with nature as it represented God, and as a constant in their lives, the women were familiar with and comfortable with their surroundings, which offered them feelings of safety and mastery (Cookman, 1996).

The women's nature trajectories were heterogeneous, but a common thread among them was their belief in nature as God's creation. As a context that evoked their spirituality, time spent with nature allowed them to experience support from, and connection to God. All of the women enjoyed a firm attachment to nature that had been established early on, and for half the women, the strength of the attachment grew over the course of their lives.

\section{Environmental Destruction}

Each generation experiences the natural environment within the social and political context of their particular cohort. How the broader cultural context shapes individual experiences is further influenced by communities, friends, and family (Elder, 1978). In relation to 
environmental concerns, the women perceived the current economic paradigm as wasteful and destructive. Influenced by the great depression, they were raised with a strong conservation ethic instilled in them as young children or adolescents (Schor, 2004). The women shared memories from their childhood when they were told to be mindful and not waste precious resources. By 1939, the Depression had ended, but a few short years later, the women were dealing with the economic perils of World War II. Since the end of the Second World War, the women lived through relatively prosperous times, but their conservative ethic persisted. About half of the women identified with, and still operated under this cognitive schema and they interpreted current environmental problems through this conservative lens.

The women's top environmental concerns were excess consumption and the waste produced as a result, and damage to the planet caused by humans either in the pursuit of progress or by human neglect. No clear pattern emerged between the women's personal relationship with nature and their sense of concern for other environmental problems, such as climate change. Collectively, the women felt they did not know enough about 'global' environmental problems, and questioned what impact they could have. Overall, the women were concerned about how much damage was being done by human activity, and unlike findings reported by Wright et al. (2003), the women did not trust industry or business to care for the natural environment. Just more than one-half of the women worried about preservation and criticized others for not taking better care. Often, however, they themselves did not know what they could do to protect nature, but engaged in behaviors they felt were beneficial (e.g., recycling), and nurtured nature in ways that were manageable and enjoyable (e.g., feeding the birds). 


\section{Accepting Responsibility: Sustainability and Control}

At the United Nations General Assembly in 1987, the chairman of the World

Commission on Environment and Development referred to sustainable development as meeting the needs of the present generation, without compromising the ability of future generations to meet their needs (Brundtland, 1987). Several authors have called for older adults to take responsibility for environmental issues and engage in environmentally based civic activities, referring to sustainability as the ultimate intergenerational concern (Benson, 2000; Ekstrom et al., 2001; Freedman, 1999). A number of questions surrounding this call to action remain unanswered. For example, do older adults feel a responsibility to future generations? For the women in this study, there was an absence of responsibility for future generations. As a group, the women were not thinking about their legacy. Their primary focus was on their own lives and current environmental conditions. About one-third of the women were concerned about the need to preserve nature, but it was directed toward the present day. Only 5 of the 34 women interviewed voiced concern about the legacy they were leaving for future generations.

Educational attainment appears to be associated with one's level of concern for the environment and sense of responsibility for future generations (Dietz et al., 1998; Oskamp, 2000). The women in this study who verbalized the most concern about sustainability were all college educated. At the other end of the spectrum, where environmental problems were not mentioned, six women reported less formal education. Four of the six women had graduated from high school, one reported some high school, and one woman had not completed elementary school. The responses of these women were different than the rest. While most women were concerned and felt helpless, uncertain, and angry, these women were simply indifferent. The common "not in my back yard" syndrome echoed in their narratives. They simply did not appear 
to pay attention, or care about what was happening. They heard about environmental issues on television, but did not perceive the issues as influencing their lives.

Another group of women who did not accept personal responsibility for the environment were the few who relied on God to take control of their lives and the planet on which they lived. Placing God in control is a way to defer personal responsibility, which can have both positive and negative outcomes (Underwood, 1999). At an emotional level, relinquishing control to God allows relief from heavy burdens, which can have a positive influence on health (Krause, 2006), but at the intellectual level, allowing God responsibility can reinforce negative beliefs and behaviors. For example, some of the women not concerned about environmental problems accepted the teachings of God and took comfort in their beliefs that He was in control and would not destroy the world. Although such explanations alleviated their worries, it often left them apathetic toward human activity and the influence they could have on the planet. Thus, faithbased explanations for environmental problems that ignore scientific evidence that certain human activities harm natural resources may leave the women feeling powerless to affect change.

\section{Limitations}

Findings from this study contribute new knowledge about the ways in which older women perceive and respond to the natural environment. The research, however, is not without its limitations. First, it was curious that the women's responses about nature were mostly positive. With the exception of concern about natural disasters and war, the women reacted positively or in a matter-of-fact-way when questioned about the importance of nature. Farm work can be backbreaking, and adverse weather can leave rural residents isolated, yet the stories these women told about their relationship to nature reflected respect and a genuine love for nature. I offer two possible explanations for the absence of negative case scenarios. First, after four points 
of contact, this group of women represented a particular sub-set of rural women. They were proud that they had work hard throughout their lives and had developed a high tolerance for both physical and emotional challenges. Their strategy for managing adversity involved focusing their energy on the positive. Although environmental problems caused the women concern, the salience of the role of nature at this point in their development revolved around their relationship with nature: their connectedness to a higher being. Second, communicating thoughts and feelings about the importance of nature can be a challenging task (Kaplan \& Kaplan, 1989). Nature is an abstract subject to reflect upon, and asking women whose lives were so entrenched in nature to articulate why it is important was a daunting task.

Second, due to the nature of the interview protocol (semi-structured questions and openended questions), not all of the women were questioned about change over time in relationship to a specific question. The protocol was arranged so the question was posed after the women responded to the question about how important nature was to them and why. The majority of women responded with their personal relationship to nature in mind, but some responded with their concerns about the environment. When that was the case, the women were asked if their level of concern had changed over time. Inconsistent questioning leaves the scope of the themes in question. However, in qualitative research the analysis of the responses is what is important and takes precedence over the number of times a particular response is given (Rossman \& Rallis, 2003). The trustworthiness and credibility of the analysis process was strengthened by having a skilled colleague assist with the initial coding of the data, by developing thick rich description, using constant comparison, remaining aware of my role as the research instrument, and documenting hunches, themes and ideas that emerged from the data (Allen, 2000; Anfara, 2002). 
Another limitation with the interview protocol involves the use of language. I specifically asked the women how concerned they were about the state of the global environment. By posing the question using the word "global", I may have shaped the women's responses. In essence, I was asking them not to think about their near environment, which is how the women thought about nature. If I had asked if they were concerned about the environment, their responses may have been different and some of the women who replied they were not concerned may have responded with concerns. The use of language is important for studying environment-related issues. Researchers need to be careful to avoid associating an individual's relationship to the natural environment with a particular stigma. The terms "environmentalist" and "environmentalism" are labels for a social movement and its members. The use of these words may conger negative images of radical activists spiking trees or chaining themselves to bulldozers. In order to more accurately assess thought and behavior patterns, more neutral language needs to be used with study participants (Gergen, 2003).

Fourth, the women in this study were chosen as part of a larger project investigating health-related issues in later life. They were selected based on the presence of specific health conditions (i.e., diabetes, heart disease, or osteoporosis). While it is common for older adults to experience health problems in later life, it is possible the presence of conditions may bias the women's perceptions of nature and environmental concern. It is not clear, for example, if some of the ways in which the women interacted with nature (e.g., sitting on the porch listening to the birds) resulted from limitations associated with their health conditions. However, the women's narratives also added a new perspective to the literature on fundamental orientations to nature. Often, researchers rely on samples of individuals who are already involved in protection efforts. Selecting the sample based on health, rather than environment-related criteria, expanded 
understanding about how environmental care and concern is born and develops amongst the general population. This new information will provide parents, educators, policy makers, and others involved in raising and educating young children, with insights about how to instill positive environmental ethics (Wells \& Lekies, 2006).

Finally, there is a lack of geographical and ethnic diversity, which limits the scope of the findings. However, the goal of qualitative research is not to generalize, but to better understand the details of a phenomenon. What is important in qualitative research is how well findings will transfer from the population studied to other like populations. Thick, rich description of the data and findings, plus a detailed description of theory and methods have been provided so other researchers can examine and assess how useful the women's insights are for their investigation (Rossman \& Rallis, 2003).

\section{Future Research}

The spiritual and psychological benefits of interacting with nature continuously reinforced a strong emotional bond that the women had developed with nature over the course of their lives. The heterogeneity of the findings support the life course framework, which posits increased diversity over time as individuals experience and define their lives in unique ways, however, it also precluded clear relationships or patterns between how the women perceived nature as beneficial and their perceptions of environmental concern. As researchers continue to pursue nature and the natural environment as an area of study in late life, they need to make their theoretical assumptions and predictions explicit. The explicit use of theory will strengthen the formulation of research questions and hypotheses, improve selection of variables, and deepen the interpretation of results (Roberto, Blieszner, \& Allen, 2006). 
Spirituality was the foundation of the women's beliefs about the world they live in. They interpreted their lives, including the role of nature, through this lens. Previous findings investigating the relationship between religiosity or spirituality and environmentalism are inconsistent (Dietz et al., 1998; Stern, 2000), but there is support for the importance of religion as a factor influencing environmental attitudes and concern (Wright et al., 2003). Because it a complex phenomenon, and can have such a powerful influence, understanding the role of religion and spirituality in relationship to environmental concern is paramount for future research.

Although not part of the original interview protocol, a question about spirituality was added very early on in the data collection process after several women's responses suggested a connection between spirituality and their beliefs about nature. In hindsight, it struck me that women who volunteered a relationship with God through nature may be telling a different story than those who were asked directly. Volunteering a spiritual relationship with nature may suggest a deeper level of connection with God through nature, it could reflect the depth of the role religion plays in their daily lives, or it could speak to the women's level of comfort with expressing their religious beliefs. To untangle this relationship, future research needs to explore the women's level of devotion and how that relates to how much and why they value nature.

One of the contributions this investigation makes to the literature on fundamental orientations to nature is the influence of life experiences after childhood. A comprehensive search of the research literature found only one other investigation on orientations guided by the life course framework, which focused on the influence of childhood experiences and how they related to later life environmentalism (Wells \& Lekies, 2006). Because of the contributions of this study, the literature now extends past childhood and suggests ways environmental values, 
attitudes, and concerns may be influenced by events in adulthood. The women in this study explained that both significant life events, such as marriage, moving, or a change in health status, and social relationships, such as new friendships or spending time with family outdoors, influenced the degree with which they valued nature. Future research should continue to use the life course perspective to explore nature trajectories. Understanding the influences that shape nature trajectories over the life course will help inform professionals involved in the effort to foster sustainability in adults. If researchers can provide evidence-based findings that later life events are influential for growing environmental ethics, concern, interest, and so forth, there is a greater likelihood that intervention programs promoting environmental education and awareness in adulthood will receive financial support.

Some women reported a heightened level of concern for nature based on their increased attention to, or knowledge about, environmental issues. They attributed their knowledge to either media or a role model, but it is not clear from the data if there was also a developmental shift occurring. It is possible that the women who had become less focused on the material world and on themselves, while at the same time more selective about activities and social experiences were engaged in the developmental process of Gerotranscendence and had turned some of their attention outward toward the natural environment (Stern, 2000). Guided by this theory, exploring change in levels of environmental concern would extend the utility of this theory and may offer additional insights for practitioners and community organizers seeking to encourage older adults to engage in environment-based volunteer activities.

\section{Implications for Practice}

The women in this study valued nature and they were concerned about environmental problems, but those qualities alone were not enough to motivate them toward community 
engagement. Their common message was they did not know what they could do about environmental problems. Educating older women living in rural areas has the potential to result in action, and providing formal volunteer opportunities to them so they can nurture nature in ways that are beneficial for their communities could improve their quality of life as they exercise their perceived roles as stewards of God's creation. Delivering education and supporting volunteer programs will require creative thinking from both formal and informal networks.

Formal policy may need to be enacted to support a regionally based program that will provide local communities across America with educational support and assistance in facilitating local environmental initiatives. Currently the RSVP program, administered through Senior Corp (a federally funded initiative to coordinate volunteer opportunities for older adults), connects older adults with service opportunities in their communities, which cover a range of interests. A project director could be added to every RSVP office in the nation to provide education and support for older adults who would like to learn about and potentially get involved with locally identified environmental problems. This type of position and resulting programs would stimulate local economies by providing employment, increasing awareness of environmental problems, providing opportunities for older adults to become engaged in their communities, and improving local environments.

Informal networks also need a call to action. As family members, individuals can take responsibility and begin (or continue) a dialogue with other family members and friends of all ages. Breaking down generational boundaries, which may seem like barriers, will help transfer important knowledge and information about nature. As the women in this study demonstrated, older adults have unique experiences that could help inform and inspire younger generations toward more conservative behaviors. Spending time together outside with other families and 
friends will provide necessary opportunities to share stories and build community. Remaining in isolation of one another will only serve to perpetuate the norm, and what is need is a paradigm shift away from competition and profit toward cooperation and care. Spending time in nature, in conversation with a loved one, is a good place to start.

From families to God, the influence of religion on the women's daily lives was pervasive. In rural areas across America, local pastors need to make sustainability a priority. Churches are powerful institutions that influence a great number of individuals and families across America and if positive messages to conserve, preserve, and care about the environment come from their respected religious leaders, members are likely to take the issues seriously. These women already perceive nature as God's creation, but they needed information and encouragement to take this belief a step further. Churches are places where communities share information about actions toward environmentally friendly behaviors. Leaders of local churches in rural America, and the more public religious figures, should fully embrace their role as God's steward, take ownership of environmental problems, and take action toward fostering a sense of responsibility in their members.

The older rural women interviewed for this project enjoyed a strong and positive relationship with the natural environment in which they lived. Nature was an important part of their self-identity. The continuity of their relationship to nature, in addition to the daily benefits they received, supported their psychological well being and provided opportunities for creativity, mastery, privacy, and security (Cookman, 1996; Kaplan, 1995; Williams et al.,1992). The women in this study lived in rural counties designated Health Professional Shortage Areas, suggesting limitations to accessing to health care. Continued effort at reorganizing rural health care delivery is warranted and should be a priority so older rural adults can safely remain in their 
homes and communities for as long as possible. For those that leave their homes to receive services elsewhere, access to nature will remain important for them. The women in this study who experienced a move in late life continued to value nature and desired interaction, and affirmed that even if their mobility was compromised, they could still enjoy the positive outcomes of interacting with nature. Administrators of the 'places' the women go to need to appreciate the benefits of nature and make access and opportunity to engage in nature a priority. 


\section{REFERENCES}

Allen, K. R. (2000). A conscious and inclusive family studies. Family Journal of Marriage and the Family, 62, 4-17.

Altman, I. (1997). Environment and behavior studies: A discipline? Not a discipline? Becoming a discipline? In S. Wapner, J. Demick, T. Yamamoto, \& T. Takahashi (Eds.), Handbook of Japan-United States environment-behavior research: Toward a transactional approach (pp. 423-434). New York: Plenum Press.

Altman, I., \& Low, S. M. (1992). Place attachment. New York: Plenum Press.

Anfara, V. A., Brown, K. M., \& Mangione, T. L. (2002). Qualitative analysis on stage: Making the research process more public. Educational Researcher, 31, 28-38.

Behringer, B., \& Friedell, G. H. (2006) Appalachia: Where place matters in health. Preventing Chronic Disease [serial online]. Retrieved August 16, 2009 from http://www.cdc.gov/ pcd/issues/2006/oct/06_0067.htm.

Bengtson, V. L., \& Allen, K. R. (1993). The life course perspective applied to families over time.

In P. G. Boss, W. J. Doherty, R. LaRossa, W. R. Schumm, \& S. K. Steinmetz (Eds.), Sourcebook of family theories and methods (pp. 469-499). New York: Plenum.

Bengtson, V. L., Putney, N. M., \& Johnson, M. L. (2005). The problem of theory in gerontology today. In M. L. Johnson (Ed.), The Cambridge handbook of age and ageing (pp. 3-20). Cambridge, UK: Cambridge University Press.

Benson, W. F. (2000). Empowerment for sustainable communities: engagement across generations. Sustainable Communities Review, 3, 11-16.

Blieszner, R., Roberto, K. A., \& Singh, K. (2001-2002). The helping networks of rural elders: Demographic and social psychological influences on service use. Ageing International, 27, 89-119. 
Bonnes, M., \& Bonaiuto, M. (2002). Environmental psychology: From spatial physical environment to sustainable development. In R. B. Bechtel, \& A. Churchman (Eds.), The handbook of environmental psychology (pp. 28-54). New York: Wiley.

Bradley, P., Walbeck, E., \& Ghiloni, J. (2004). Proceedings of the aging Americans: Impacts ecology and environmental quality workshop. Washington, DC: The Environmental Protection Agency.

Brundtland, G. H. (1987). Report of the World Commission on Environment and Development: Our common future. Retrieved July 31, 2009, from http://www.un-documents.net/wcedocf.htm

Buttel, F. H. (1979). Age and environmental concern: A multivariate analysis. Youth and Society, 10, 237-256.

Central Intelligence Agency (2007). The world fact book. Retrieved September 12, 2007, from https://www.cia.gov/library/publications/the-world-factbook/print/xx.html Charmaz, K. (2006). Constructing grounded theory: A practical guide through qualitative analysis. Thousand Oaks: Sage.

Cookman, C. A. (1996). Older people and attachment to things, places, pets, and ideas. Journal of Nursing Scholarship, 28, 227-231.

Coyne C. A., Demian-Popescu, C., Friend, D. (2006). Social and cultural factors influencing health in southern West Virginia: a qualitative study. Preventing Chronic Disease [serial online]. Retrieved August 16, 2009 from http://www.cdc.gov/pcd/issues/2006/oct/06_ 0030.htm.

Dietz, T., Stern, P., \& Guagnano, G. (1998). Social structure and social psychological bases of environmental concern. Environment and Behavior, 30, 450-471. 
Dunlap, R. E., Van Liere, K. D., Mertig, A. G., \& Jones, R. E. (2000). Measuring endorsement of the New Ecological Paradigm: A revised NEP scale. Journal of Social Issues, 56, $425-$ 442.

Dutcher, D. D., Finley, J. C., Luloff, A. E., \& Johnson, J. B. (2007). Connectivity with nature as a measure of environmental values. Environment and Behavior, 39, 474-493.

Ekstrom, C. D., Ingman, S. R., \& Benjamin, T. (2001). The global ecology and the older adult in the $21^{\text {st }}$ centrury: Senior involvement in sustainability achievement. The Indian Journal of Gerontology, 15, 244-254.

Elder, G. (1978). Family history and the life course. In T. K. Hareven (Ed.), Transitions: The family and the life course in historical perspective (pp. 17-64). New York: Academic Press.

Elder, G. H. (1998). The life course as developmental theory. Child Development, 69, 1-12.

Frederickson, L. A., \& Anderson, D. H. (1999). A qualitative exploration of the wilderness experience as a source of spiritual inspiration. Journal of Environmental Psychology, 19, 21-39.

Freedman, M. (1999). Prime time: How baby boomers will revolutionize retirement and transform America. New York: Public Affairs.

Frumkin, H. (2001). Beyond toxicity: Human health and the natural environment. American Journal of Preventive Medicine, 20, 234-240.

Frumkin, H. (2003). Healthy places: Exploring the evidence. American Journal of Public Health, 93, 1451-1456.

Garst, B. A. (2005). An exploration of developed forest camping experiences and meanings in the Mount Rogers National Recreation Area (Doctoral dissertation, Virginia Tech, 2005). 
Gatz, M. \& Zarit, S. H. (1999). A good old age: Paradox or possibility. In V. L. Bengtson \& K. W. Schaie (Eds.), Handbook of theories in aging (pp 396-416). NY: Springer Publishing.

Gergen, K. J. (2003). An invitation to social construction. Thousand Oaks: Sage.

Gifford, R. (2002). Making a difference: Some ways environmental psychology has improved the world. In R. B. Bechtel, \& A. Churchman (Eds.), The handbook of environmental psychology (pp. 28-54). New York: Wiley.

Gigliotti, C. M., \& Jarrott, S. E. (2005). Effects of horticulture therapy on engagement and affect. Canadian Journal on Aging, 24(4), 49-59.

Hartig, T., Evans, G. W., Jamner, L. D., Davis, D. S., \& Garling, T. (2003). Tracking restoration in natural and urban field settings. Journal of Environmental Psychology, 23, 109-123.

Hartig, T., Kaiser, F. G., \& Bowler, P. A. (2001). Psychological restoration in nature as a positive motivation for ecological behavior. Environment and Behavior 33, 590-607.

Hartig, T., Mang, M., \& Evans, G. W. (1991). Restorative effects of natural environment experiences. Environment and Behavior, 23, 3-26.

Honnold, J. A. (1984). Age and environmental concern: Some specification of effects. Journal of Environmental Education, 16, 4-9.

Ignatow, G. (2006). Cultural models of nature and society: Reconsidering environmental attitudes and concern. Environment and Behavior, 38, 441-461.

Intergovernmental Panel on Climate Change. (2007). Summary for policymakers. In B. Metz, O. R. Davidson, P. R. Bosch, R. Dave, \& L. A. Meyer (Eds.), Climate change 2007: Mitigation. Contribution of working group III to the fourth assessment report of the Intergovernmental Panel on Climate Change. Retrieved January 13, 2008, from http://www.ipcc.ch/ipccreports/ar4-wg3.htm 
Jansen, D. A., \& von Sadovszky, V. (2004). Restorative activities of community-dwelling elders. Western Journal of Nursing Research, 26, 381-399.

Kaplan, R. (2001). The nature of the view from home: Psychological benefits. Environment and Behavior, 33, 507-542.

Kaplan, S. (1995). The restorative benefits of nature: Toward an integrative framework. Journal of Environmental Psychology, 15, 169-182.

Kaplan, S., \& Kaplan, R. (1989). The experience of nature: A psychological perspective. New York: Cambridge University Press.

Knopf, R. C. (1987). Human behavior, cognition, and affect in the natural environment. In D. Stokols, \& I. Altman (Eds.), Handbook of environmental psychology (pp. 783 - 825). New York: Wiley.

Krause, N. (2006). Religion and health in late life. In J. Birren, \& K. W. Schaie (Eds.), Handbook of the psychology of aging $\left(6^{\text {th }}\right.$ ed.) (pp. 500-518). New York: Academic Press.

Kweon, B., Sullivan, W. C., \& Wiley, A. R. (1998). Green common spaces and the social integration of inner-city older adults. Environment and Behavior, 30, 832-859.

Louv, R. (2005). Last child in the woods: Saving our children from nature-deficit disorder. Chapel Hill, NC: Algonquin Books.

Manzo, L. C. (2003). Beyond house and haven: Toward a revisioning of emotional relationships with places. Journal of Environmental Psychology, 23, 47-61.

Mohai, P., \& Twight, B. W. (1987). Age and environmentalism: An elaboration of the Buttel model using national survey evidence. Social Science Quarterly, 68, 798-815.

Moore, E. O. (1981). A prison environment's effect on health care service demands. The Journal of Environmental Systems, 2, 17-34. 
Muhr, T. (2004). ATLAS.ti (Version 5.0) [Computer software]. Berlin: Scientific Software Development.

Oskamp, S. (2000). Psychological contributions to achieving an ecologically sustainable future for humanity. Journal of Social Issues, 56, 373-390.

Ottosson, J., \& Grahn, P. (2005). Measures of restoration in geriatric care residences: The influence of nature on elderly people's power of concentration, blood pressure, and pulse rate. Journal of Housing for the Elderly, 19, 227-256.

Roberto, K.A. (2009). Placing developmental paradigms in context: Health and adaptation in late life. In J.A. Mancini \& K. A. Roberto (Eds.), Pathways of human development: Explorations of change (pp. 127- 147). Lanham, MD: Lexington Books.

Roberto, K. A., Blieszner, R., \& Allen, K. R. (2006). Theorizing in family gerontology: New opportunities for research and practice. Family Relations, 55, 513-525.

Roberto, K. A., Gigliotti, C. M., \& Husser, E. K. (2005). Rural older women's experiences with chronic health problems: Daily challenges and care practices. Health Care for Women International, 26, 672-692.

Roberto, K. A., \& Husser, E. K. (2007). Social relationships: Resources and obstacles to older women's health adaptations and well-being. In T. J. Owens, \& J. J. Suitor (Eds.), Advances in life course research: Interpersonal relations across the life course (pp. 383410). New York: Elsevier Science.

Rossman, G. B., \& Rallis, S. F. (2003). Learning in the field: An introduction to qualitative research. Thousand Oaks: Sage.

Rubenstein, R. L., \& Parmelee, P. A. (1992). Attachment to place and the representation of the life course by the elderly. In I. Altman \& S. Low (Eds.), Place attachment (pp. 139-163). 
New York: Plenum Press.

Schor, J. (2004). Older consumers and the ecological dilemma. Harvard Generations Policy Journal, 1, 79-90.

Scopelliti, M., \& Guiliani, M. V. (2005). Restorative environments in later life: An approach to well-being from the perspective of environmental psychology. Journal of Housing for the Elderly, 19, 203-226.

Stern, P. C. (2000). Toward a coherent theory of environmentally significant behavior. Journal of Social Issues, 56, 407-424.

Talbot, J. F., \& Kaplan, R. (1991). The benefits of nearby nature for elderly apartment residents. International Journal of Aging \& Human Development, 33, 119-130.

Tang, J. W., \& Brown, R. D. (2005). The effect of viewing a landscape on physiological health of elderly women. Journal of Housing for the Elderly, 19, 187-202.

Tennessen, C. M., \& Cimprich, B. (1995). Views to nature: Effects on attention. Journal of Environmental Psychology, 15, 77-85.

Tornstam, L. (2009). The theory of Gerotranscendence. Retrieved August 21, 2009, from: http://www.soc.uu.se/research/gerontology/gerotrans.html

Ulrich, R. S. (1984). View from a window may influence recovery from surgery. Science, 224, 420-422.

Underwood, L. G. (2003). Daily spiritual experiences. In Multidimensional measurement of religiousness/spirituality for use in health research: A report of the Fetzer Institute/National Institute on Aging Working Group. Retrieved June 15, 2009, from: www.fetzer.org/PDF/Multidimensional_Update.pdf

United States Environmental Protection Agency. (2007). Aging initiative. Retrieved March 17, 
2008, from http://www.epa.gov/aging

Vaske, J. J., \& Kobrin, K. C., (2001). Place attachment and environmentally friendly behavior. Journal of Environmental Education, 32, 16-21.

Watkins, M. (2000). Ways of learning about leisure meanings. Leisure Sciences, 22, 93107.

Wells, N. M., \& Lekies, K. S. (2006). Nature and the life course: Pathways from childhood nature experiences to adult environmentalism. Children, Youth, and Environments, 16, 125.

Whall, A. L., Black, M. E., Groh, C. J., Yankou, D. J., Kupferschmid, B. J., \& Foster, N. L. (1997). The effect of natural environments upon agitation and aggression in late stage dementia patients. American Journal of Alzheimer's Disease, 12, 216-220.

Williams, D. R. (2008). Pluralities of place: A user's guide to place concepts, theories, and philosophies in natural resource management. In L. E. Kruger, T. E. Hall, \& M. C. Stiefel (Eds.), Understanding concepts of place in recreation research and management (pp 730). Portland, OR: U.S. Department of Agriculture, Forest Service, Pacific Northwest Research Station.

Williams, D. R., Patterson, M. E. \& Roggenbuck, J. W. (1992). Beyond the commodity metaphor: Examining the emotional and symbolic attachment to place. Leisure Sciences, $14,29-46$.

Williams, D. R., \& Vaske, J. J. (2003). The measurement of place attachment: Validity and generalizability of a psychometric approach. Forest Science, 49, 830-840.

Wright, S. D., Caserta, M., \& Lund, D. A. (2003). Older adults' attitudes, concerns, and support 
for environmental issues in the "New West". International Journal of Aging and Human Development, 57, 151-179.

Wright, S. D., \& Lund, D. A. (2000). Gray and green?: Stewardship and sustainability in an aging society. Journal of Aging Studies, 14, 229-249. 


\section{APPENDIX}

Appendix A - Institutional Review Board (IRB) Approval Form

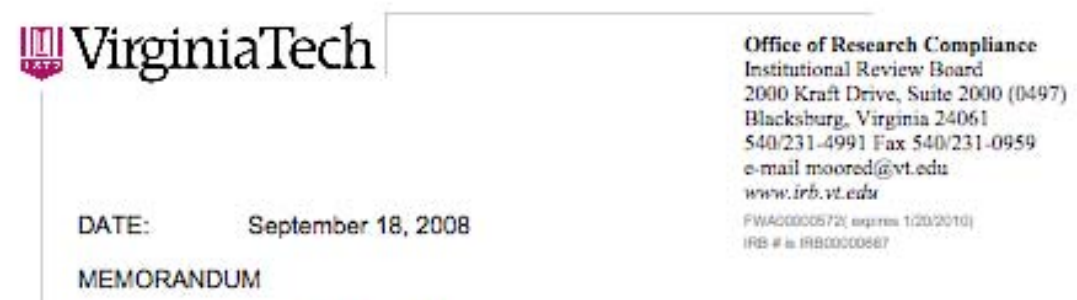

TO:

Karen A. Roberto

FROM: David M. Moore 2C2 $\begin{aligned} & \text { Approval date: 10/18/2008 } \\ & \text { Continuing Review Due Date: 10/3/2009 } \\ & \text { Expiration Date: 10/17/2009 }\end{aligned}$

SUBJECT: IRB Expedited Continuation 6: "Rural Older Virginians with Chronic Health Conditions: Behavioral and Psychosocial Influences on Quality of Life', IRB \# $05-485$

This memo is regarding the above referenced protocol which was previously granted expedited approval by the IRB. The proposed research is eligible for expedited review according to the specifications authorized by 45 CFR 46.110 and 21 CFR 56.110. Pursuant to your request, as Chair of the Virginia Tech Institutional Review Board, 1 have granted approval for extension of the study for a period of 12 months, effective as of October 18, 2008.

Approval of your research by the IRB provides the appropriate review as required by federal and state laws regarding human subject research. As an investigator of human subjects, your responsibilities include the following:

1. Report promptly proposed changes in previously approved human subject research activities to the IRB, including changes to your study forms, procedures and investigators, regardless of how minor. The proposed changes must not be initiatec without IRB review and approval, except where necessary to eliminate apparent immediate hazards to the subjects.

2. Report prompty to the IRB any injuries or other unanticipated or adverse events involving risks or harms to human research subjects or others.

3. Report promptly to the IRB of the study's closing (i.e., data collecting and data analysis complete at Virginia Tech). If the study is to continue past the expiration date (listed above), investigators must submit a request for continuing review prior to the continuing review due date (listed above). It is the researcher's responsibility to obtain re-approval from the IRB before the study's expiration date.

4. If re-approval is not obtained (unless the study has been reported to the IRB as closed) prior to the expiration date, all activities involving human subjects and data analysis must cease immediately, except where necessary to eliminate apparent immediate hazards to the subjects. 
Appendix B - Demographic Information

Table 1. Demographic information

\begin{tabular}{|c|c|c|c|c|c|c|}
\hline Pseudonym & Age & Years in County & Marital Status & Living Situation & Monthly Income & Education \\
\hline Agnus & 87 & 40 & Widowed & Son & $\$ 2000$ - 2999 & Grade school \\
\hline Barbara & 91 & 61 & Widowed & Alone & $\$ 1001-1999$ & Grad school or professional degree \\
\hline Crystal & 84 & 52 & Married & Husband & $\$ 2000-2999$ & Some college \\
\hline Dale & 75 & 49 & Widowed & Son & $<\$ 750$ & High school grad (or GED) \\
\hline Alysia & 80 & 60 & Married & Husband & $\$ 2000-2999$ & Some college \\
\hline Emily & 73 & 55 & Widowed & Alone & $\$ 1001-1299$ & Some college \\
\hline Faith & 79 & 73 & Married & Husband & $>\$ 4000$ & High school grad (or GED) \\
\hline Fatima & 71 & 66 & Divorced & Alone & $<\$ 750$ & Some high school \\
\hline Gail & 77 & 71 & Divorced & Alone & $\$ 1001-1999$ & Trade/Voc school after HS \\
\hline Hilda & 80 & 55 & Widowed & Alone & $\$ 751-1000$ & Trade/Voc school after HS \\
\hline Imogene & 85 & 2 & Widowed & Alone & $\$ 751-1000$ & High school grad (or GED) \\
\hline Jodi & 81 & 65 & Married & Husband & $\$ 3000-3999$ & Grade school \\
\hline Josylen & 83 & 68 & Widowed & Alone & $\$ 751-1000$ & High school grad (or GED) \\
\hline Katy & 72 & 45 & Widowed & Alone & $<\$ 750$ & Less than grade school \\
\hline Leanne & 89 & 83 & Widowed & Alone & $>\$ 4000$ & High school grad (or GED) \\
\hline Melissa & 75 & 47 & Married & Husband & $\$ 751-1000$ & Completed Community College \\
\hline Nadia & 71 & 65 & Widowed & Daughter & $\$ 1001-1999$ & Completed Community College \\
\hline Noel & 75 & 55 & Divorced & Daughter & $\$ 1001-1999$ & Grad school or professional degree \\
\hline Odessa & 83 & 28 & Single & Alone & $>\$ 4000$ & Grad school or professional degree \\
\hline Ophelia & 73 & 50 & Married & Husband & $\$ 2000-2999$ & High school grad (or GED) \\
\hline Pete & 81 & 70 & Married & Husband & $\$ 3000-3999$ & Some college \\
\hline Patsy & 86 & 8 & Widowed & Alone & $\$ 1001-1999$ & High school grad (or GED) \\
\hline Rhonda & 81 & 75 & Widowed & Alone & $\$ 751-1000$ & High school grad (or GED) \\
\hline Sidney & 73 & 11 & Married & Husband & $\$ 1001-1999$ & Some college \\
\hline Simone & 74 & 50 & Widowed & Alone & $\$ 751-1000$ & College graduate \\
\hline Unice & 76 & 52 & Married & Husband & $\$ 2000-2999$ & High school grad (or GED) \\
\hline Udele & 82 & 2 & Married & Husband & $>\$ 4000$ & High school grad (or GED) \\
\hline Violet & 86 & 74 & Widowed & Alone & $\$ 1001-1999$ & High school grad (or GED) \\
\hline Wanetta & 84 & 47 & Widowed & Alone & $\$ 1001-1999$ & Some college \\
\hline Winifred & 83 & 14 & Married & Husband & $\$ 1001-1999$ & High school grad (or GED) \\
\hline Yolanda & 81 & 51 & Widowed & Alone & $\$ 1001-1999$ & High school grad (or GED) \\
\hline
\end{tabular}




\section{Appendix C - Interview Protocol}

We've been talking about your social circle, now I would like to ask you some questions about your thoughts on the natural environment.

1. On a scale of $0-6$, how important would you say the natural environment is to you? (0 being not important at all, 6 being extremely important)

$$
\begin{array}{lllllll}
0 & 1 & 2 & 3 & 4 & 5 & 6
\end{array}
$$

Probe (use only if there is confusion): natural environment is defined as flora and fauna so the flowers, trees, hills and valleys

2. What did you think of when I said natural environment; how do you define natural environment? Why is nature important to you? Have you always felt this way or have your feelings and beliefs about the natural environment changed over the course of your life?

3. Is there a spiritual connection for you with nature? Can you explain that to me or give me an example of when you feel that?

4. On a scale of $0-6$, how concerned are you about the state of the global environment? ( 0 being not concerned at all, 6 being extremely concerned)

$\begin{array}{lllllll}0 & 1 & 2 & 3 & 4 & 5 & 6\end{array}$

5. What are you concerned about at the global level (concern about the planet)? 